\title{
Review of Push-Out and Shear Response of Hybrid Steel-Trussed Concrete Beams
}

\author{
Piero Colajanni *(D), Lidia La Mendola and Alessia Monaco \\ Department of Civil, Environmental, Aerospace, Materials Engineering, University of Palermo, \\ Palermo I-90128, Italy; lidia.lamendola@unipa.it (L.L.M.); alessia.monaco@unipa.it (A.M.) \\ * Correspondence: piero.colajanni@unipa.it; Tel.: +39-091-238-96550
}

Received: 26 July 2018; Accepted: 19 September 2018; Published: 24 September 2018

\begin{abstract}
The hybrid steel trussed concrete beams examined in the present study are comprised of two principal components, i.e., a steel joist with inclined rebars, realized in industry, which is welded to a smooth steel plate and then embedded within the concrete cast in situ. The paper presents first the state of the art on laboratory tests and analytical modeling of the steel-to-concrete stress transfer mechanism investigated by push-out tests. Next, the most relevant scientific contributions currently available in the technical literature regarding experimental investigation on actual shear behavior are summarized and discussed. Lastly codes and analytical models are reviewed.
\end{abstract}

Keywords: steel concrete composite beam; precast trussed beam; push-out test; analytical models

\section{Introduction}

A Hybrid Steel Trussed Concrete Beam (HSTCB) is a structural element consisting of a lattice metal beam, with a prefabricated concrete or steel caseback, embedded in whole or in part in concrete casting in place. The main parts of the lattice are the top and bottom chords and the web. The lattice morphology can be categorized by different parameters [1]: (1) by the bottom chord, e.g., steel or precast prestressed concrete bottom chord (Figure 1a); (2) by the shape of the lattice, e.g., spatial (Figure 1a,b), plane (Figure 2a), or multi-plane lattice (Figure 1c); (3) by the size and position (compared to the slab), e.g slab thick (Figure 1d), downward (Figure 1e), or upward (Figure 1f) full thick beams; (4) by the element shape of the bottom chord, e.g., beams having bottom chords made with steel plate, steel angular (Figure 1g), or round or square bars placed on one or more layers; (5) by the morphology of the web bars, e.g., web made up by a single bar bent with a V shape (Figure 1h), composed with two elements welded to the top and bottom chords, or consisting of a continuous serpentine (Figure 1i). 


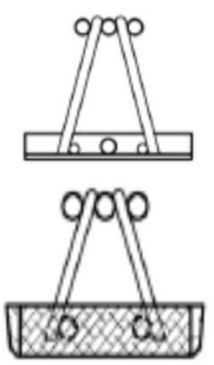

(a)

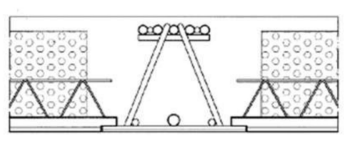

(d)

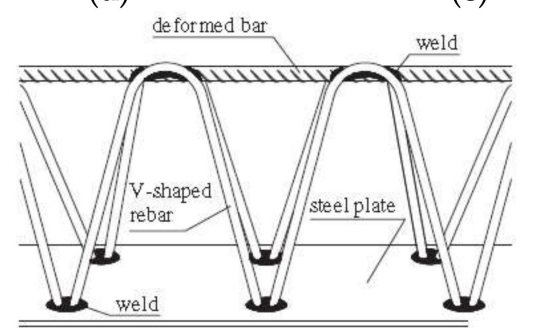

(h)

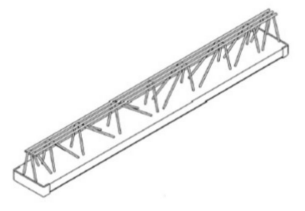

(b)

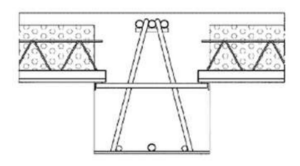

(e)

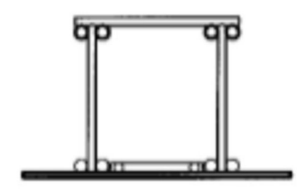

(c)

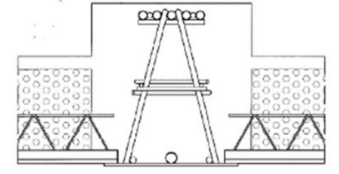

(f)

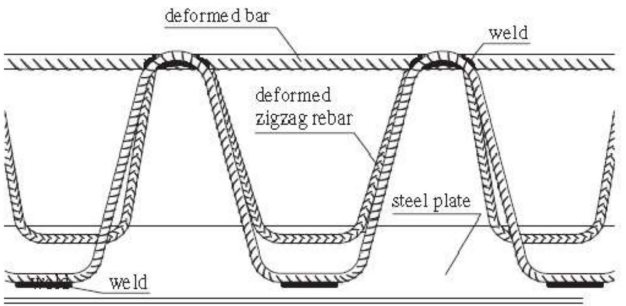

(i)

Figure 1. Beams having: (a) steel or precast prestressed concrete bottom chords; (b) spatial lattices; (c) multiplane lattices; (d-f) slab thick downward, and upward (compared to the slab) full thick beams; (g) bottom chord made by steel angular; (h) web made by a single bar bent with a V shape; or (i) consisting of a continuous serpentine.

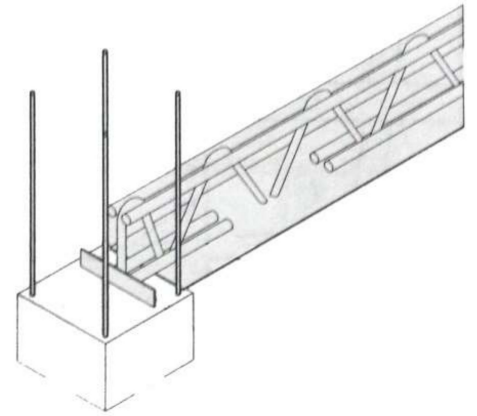

(a)

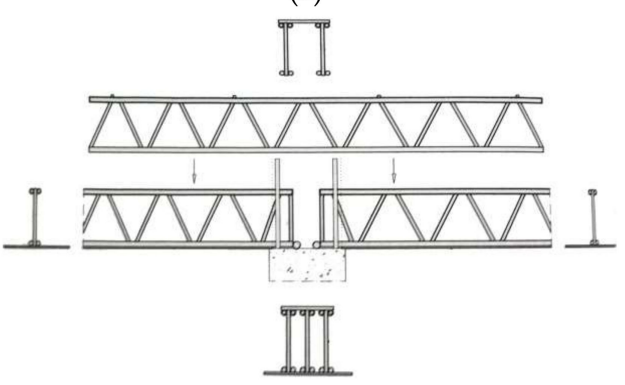

(c)

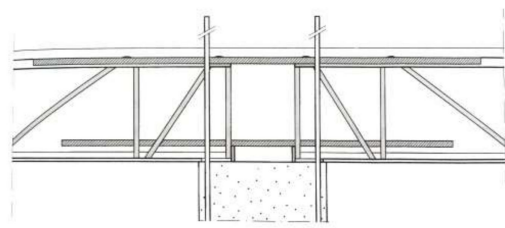

(b)

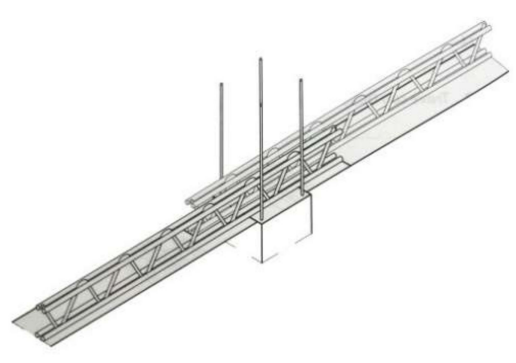

(d)

Figure 2. Connection typology at the beam-to-column joint: (a) transversal steel plate welded to the rebar welded to the bottom steel plate; (b) added top and bottom rebars; (c) added bi-planar truss; (d) two overlapping lattices positioned eccentrically. 
When the beam is inserted into a moment-resistant frame, several structural options are available to ensure the connection and the transmission of the bending moment across the beam-column joint. In a first case, connection is guaranteed at the base of the beam by connecting the bottom plate to the column by a transversal steel plate welded to the rebars, welded in turn to the bottom steel plate (Figure 2a). In other cases, added top and bottom steel rebars are utilized in order to guarantee transmission of the tensile and compressive force at the joint (Figure 2b). In a third case connection is obtained by overlapping a precast spatial lattice with two plane trusses in the joint region (Figure 2c), or lastly by overlapping two lattices positioned eccentrically with respect to the axis of the bottom chord (see Figure 2d) so that the lattice itself acts as reinforcement that guarantee connections.

An HSTCB is typically subject to three different operating phases. Phase 0 begins with construction in the factory and ends with installation (transient lifting, transport and assembly phase). Phase I is transitory (Figure 3), and begins with the beam put in place and includes the concrete casting of the beam and of the portion of deck attached thereto. Phase I lasts until the concrete reaches the preset design resistance for the beginning of Phase II. Phase II includes the whole life of the structural organism in which the HTCB is inserted (operating phase).
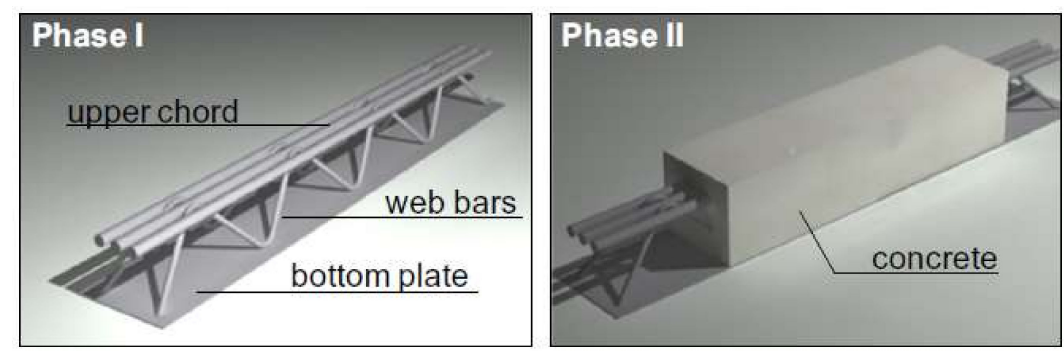

Figure 3. Beam structural schemes in operating Phases I and II.

The HSTCB represents a more and more widely used structural typology in the building construction industry thanks to economic benefits arising from excellent structural performance and rapidity of implementation. The latter derive from the partial prefabrication of the beams and from their self-supporting capacity in casting Phase 0 and Phase I. Regarding the design of such a type of beam, in the past HSTCBs were designed on the basis of the current rules for R.C. or for steel-concrete hybrid beam elements. More recently, a large number of research papers have been published, aimed at deriving specific design procedures for this beam typology. The key problems scrutinized in Phase 0 and Phase I regard estimation of the welded joint resistance [2] and the flexural and torsional stability of the lattice [3]. Meanwhile, the key problems scrutinized in Phase II regard the stress transfer mechanisms between steel and concrete [4-12], assessment of bending and shear strength [13-20], beam-column joint performance under static, cyclic [21-26] and seismic [27] loads, and assessment of deformability at short and long-term [28].

In this context, in the present paper, first the state of the art on laboratory tests and the analytical modeling of the steel-to-concrete stress transfer mechanism investigated by push-out tests are focused on. Next, the most relevant scientific contributions currently available in the technical literature regarding experimental investigation on actual shear behavior are summarized and discussed; lastly, code and analytical design-oriented models proposed in the literature are reviewed.

\section{Steel to Concrete Stress Transfer Mechanism}

\subsection{Experimental Results}

In spite of the large variety of HSTCB typologies commonly in use since 1970, in the past only a few authors presented experimental results studying the stress transfer mechanism between steel and concrete. More recently, this problem has aroused new interest, and it is usually investigated by means of experimental push-out tests that are inspired by the test procedures specified in Eurocode 4 [29] 
for conventional composite beams. Usually, the tested sample of the beam consists of (Figure $4 \mathrm{~b}$ ) a steel plate working as the bottom chord of the lattice, one or more longitudinal steel bars constituting the upper chord, and steel web bars welded to the bottom and top chords working as diagonals connecting the truss and concrete core. The bars can be either ribbed bars or smooth steel bars. As for classical push-out tests, the testing specimen consist of two equal segments of beam joined by means of an added steel plate welded perpendicularly to the truss bottom chords and properly strengthened at the end where the load is applied [4,5,7-11,29]. The main outcome of the test is load vs. slip between the concrete of the beam and added steel plate curve (Figure 5), which allows for one to evaluate the strength and ductility of the connection. Figure 4 shows the layout of the push-out tests on HSTCBs available in the technical literature. All results are used in the following sections in terms of maximum load in order to check the suitability of some analytical approaches for the assessment of the push-out test response.

The first researchers that studied the steel truss-to-concrete stress transfer mechanism in HSTCBs by push-out tests were Puhali and Smotlack (1980) [4]. They compared the performance of planar and three-dimensional trusses (Figure 4a) with different strengths of the connection (size of web rebars). More precisely, for each typology, three specimens were tested, all of them having steel plate $6 \mathrm{~mm}$ thick, and diameter of web bars $\varphi_{\mathrm{w}}$ and upper chord $\varphi_{\text {up }}$ varying in a range from $14 \mathrm{~mm}$ to $32 \mathrm{~mm}$. (Table 1). The bars and the plate were both realized with smooth steel having nominal yielding strength of $355 \mathrm{~N} / \mathrm{mm}^{2}$ (S355), while the concrete had a cubic compressive resistance varying in the range $26-30 \mathrm{~N} / \mathrm{mm}^{2}$. Table 1 shows the features of the specimens and the experimental results.

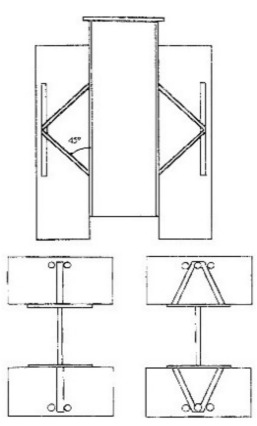

(a)

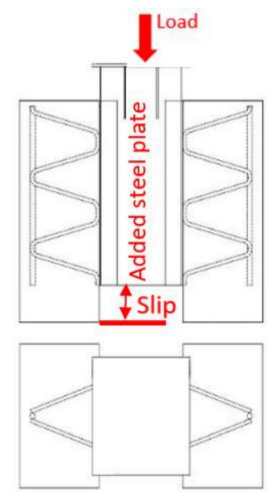

(b)

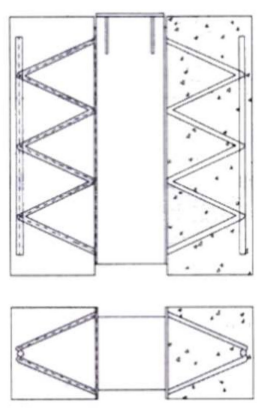

(c)

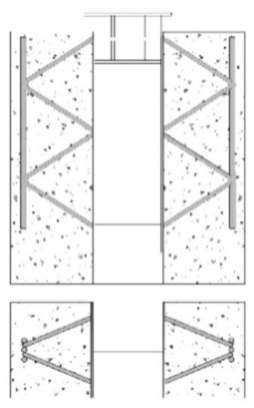

(d)

Figure 4. Geometry of specimens: (a) Puhali and Smotlack (1980) [4]; (b) Tullini and Minghini [7]; (c) Aiello [5]; (d) Badalamenti et al. [14].

Table 1. Specimen features and experimental results by Puhali and Smotlack [4].

\begin{tabular}{|c|c|c|c|c|}
\hline ID & Web Bars & Upper Chord & Ultimate Load (kN) & Failure \\
\hline A-P1 & $\begin{array}{c}\text { no.1 bar } \\
\left(\varphi_{\mathrm{w}}=14 \mathrm{~mm}\right)\end{array}$ & $\begin{array}{c}\text { no.2 bars } \\
(\varphi \text { up }=14 \mathrm{~mm})\end{array}$ & 463.0 & steel web rebars \\
\hline A-P2 & $\begin{array}{c}\text { no.1 bar } \\
\left(\varphi_{\mathrm{w}}=24 \mathrm{~mm}\right)\end{array}$ & $\begin{array}{c}\text { no. } 2 \text { bars } \\
\left(\varphi_{\text {up }}=24 \mathrm{~mm}\right)\end{array}$ & 647.5 & concrete \\
\hline A-P3 & $\begin{array}{c}\text { no.1 bar } \\
\left(\varphi_{\mathrm{w}}=32 \mathrm{~mm}\right)\end{array}$ & $\begin{array}{c}\text { no. } 2 \text { bars } \\
\left(\varphi_{\text {up }}=32 \mathrm{~mm}\right)\end{array}$ & 843.5 & concrete \\
\hline B-P4 & $\begin{array}{c}\text { no. } 2 \text { bars } \\
\left(\varphi_{\mathrm{w}}=14 \mathrm{~mm}\right)\end{array}$ & $\begin{array}{c}\text { no.3 bars } \\
\left(\varphi_{\text {up }}=14 \mathrm{~mm}\right)\end{array}$ & 735.5 & $\begin{array}{l}\text { Steel web rebars } \\
\text { and plate buckling }\end{array}$ \\
\hline B-P5 & $\begin{array}{c}\text { no.2 bars } \\
\left(\varphi_{\mathrm{w}}=24 \mathrm{~mm}\right)\end{array}$ & $\begin{array}{c}\text { no.3 bars } \\
\left(\varphi_{\text {up }}=24 \mathrm{~mm}\right)\end{array}$ & 1177.5 & concrete \\
\hline B-P6 & $\begin{array}{c}\text { no. } 2 \text { bars } \\
\left(\varphi_{\mathrm{w}}=32 \mathrm{~mm}\right)\end{array}$ & $\begin{array}{c}\text { no.3 bars } \\
\left(\varphi_{\text {up }}=32 \mathrm{~mm}\right)\end{array}$ & 1324.5 & steel plate buckling \\
\hline
\end{tabular}


The authors stressed that all specimens with space truss (B-P4, B-P5 and B-P6) exhibit both higher stiffness and strength with respect to the single planar truss counterpart (specimens A-P1, A-P2 and A-P3). In each of the two groups, specimens having rebars with small diameters (A-P1 and B-P4) exhibit low strength, but ductile behavior characterized by failure of the web bars. When spatial truss is considered, buckling of the steel plate can precede the web bar failure. Specimens with web bars of larger diameters exhibit larger strengths, but a more brittle failure mechanism characterized by a crisis of the concrete or buckling of the steel plate (Table 1).

The load-slip curves obtained for the group A and group B specimens are shown in Figure $5 \mathrm{a}, \mathrm{b}$ respectively. All specimens exhibit large initial stiffness, which decreases when slip between the steel plate and the concrete kicks in. Specimen A-P1 exhibited ductile behavior, with rupture due to cutting of the diagonal rebar of the truss, along planes parallel to the axis of the specimen, in sections close to those of welding to the plate. Models A-P2 and A-P3 showed lower ductility, as characterized by a collapse on the concrete side along planes parallel to the load axis. Collapse occurred following shear action developed by the bar of the truss on the concrete.

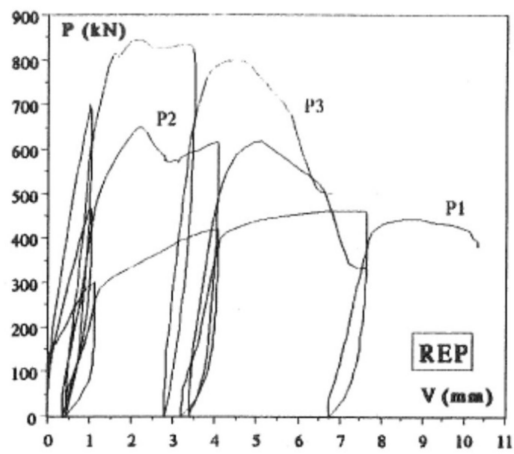

(a)

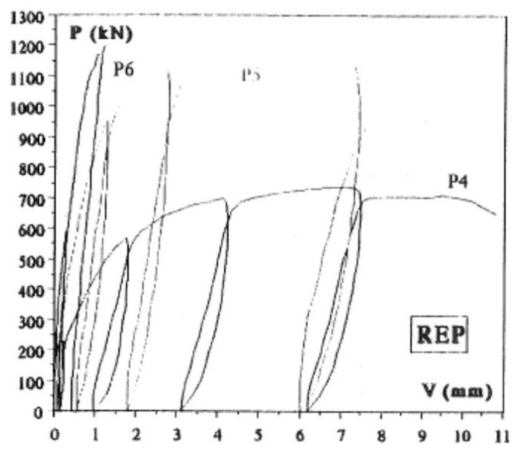

(b)

Figure 5. Load-slip curve obtained by Puhali and Smotlack [4] for: (a) group A specimens; (b) group B specimens.

The group B specimens showed much greater strength and stiffness than the corresponding group A specimens. Again, in the sample with diameter of the web diagonals $\varphi_{\mathrm{w}}=14 \mathrm{~mm}$, failure occurred due to rupture of the bars in the area of connection to the plate; in this case failure was preceded by noticeable local buckling of the steel plate. In the collapse mechanism, all the bars of the truss were strongly deformed, and in particular, the compressed diagonals and the bars of the upper chord. For sample B-P5, for which the load-slip curve (Figure 5b) shows a considerable amplitude of the slips at the failure, the ductile branch was followed by a fragile collapse, caused by sudden bursting of one of the two concrete "slabs" due to shear action exerted by the bars of the lattice on the concrete. Finally, the failure of specimen B-P6, equipped with a lattice upper chord and web bars having large diameter $\left(\varphi_{\mathrm{w}}=\varphi_{\text {up }}=32 \mathrm{~mm}\right)$, occurred due to local buckling of the steel plate.

The more recent experimental investigation carried out by Tullini and Minghini [7] stressed the key role played by the shape of the web bars, and the size of the welding. The authors tested three identical specimens (Figure 4b), whose truss was made (see Figure 6a) with a S355 4 mm thick steel plate, web bars of $12 \mathrm{~mm}$ diameter and upper chord with diameter $18 \mathrm{~mm}$. The web truss was made up of a continuous serpentine welded to the bottom plate and the bars of the upper chords. The welds on the lower plate had a throat height of $6 \mathrm{~mm}$, a length of $35 \mathrm{~mm}$ and a pitch of $200 \mathrm{~mm}$. The bars were made of steel with nominal yielding stress $440 \mathrm{~N} / \mathrm{mm}^{2}$ and the concrete had mean cubic compressive strength equal to $42.24 \mathrm{~N} / \mathrm{mm}^{2}$. The tests conducted by the authors aimed at assessing the strength, stiffness and ductility of the connection between steel and concrete. For this purpose, the authors showed the curve in Figure $6 \mathrm{~b}$ of the load absorbed by the single weld as a function of the sliding between the metal plate and the concrete, and its numerical estimation by Ollgaard's relationship. For all samples tested failure suddenly occurred, with a separation of a block of concrete from the 
plate due to the wrench of the welds between the plate and the web bar. Moreover, they stressed that the high slip gradient arising in sections near the supports may lead to premature concrete failure.

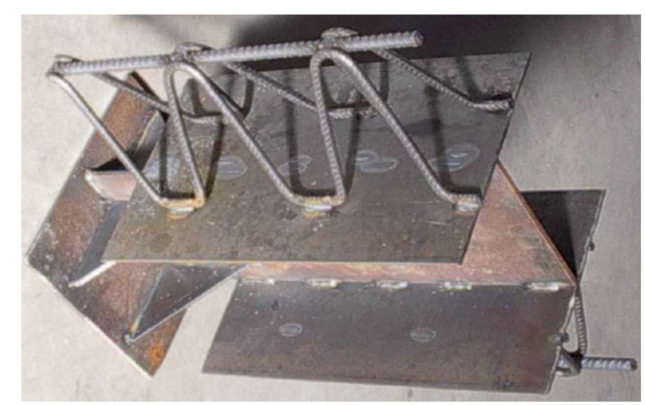

(a)

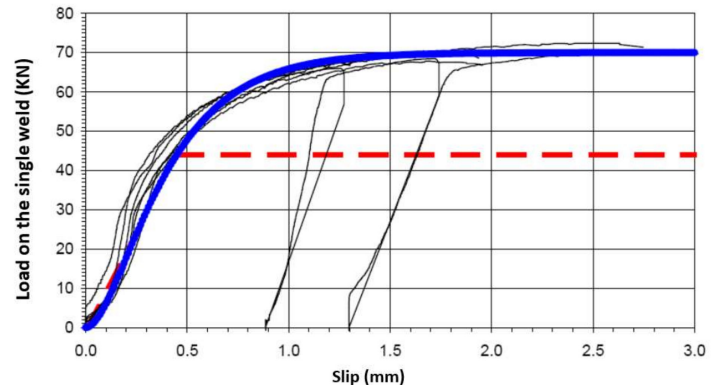

(b)

Figure 6. Push-out test by Tullini and Minghini (2013) [7]: (a) Lattice before concrete casting for testing employed; (b) Load on welding-sliding: —- experimental results; : Ollgaard's relationship.

Aiello (2008) [5], attested the efficiency of the push-out test procedure derived by EC4 [29] for conventional steel-concrete composite beams for characterizing the stiffness, strength and ductility of the connection of HSTCBs. She confirmed that the collapse can often be due to failure through under-sizing of the welding between web bars and bottom steel plate, and emphasized the role played by the finishing of the surface of the web rebar (smooth or ribbed). She advised strict checking of the bent and welding processes of the web bars during the production phase.

The experimental analysis reported here concerns eight tests on specimens of four typologies. Their characteristics are described in Table 2, where $\varphi_{\mathrm{w}}$ and $\varphi_{\mathrm{uc}}$ indicate the diameter of the diagonal bars and the upper chord, and $\mathrm{P}_{\mathrm{u}}$ is the maximum load achieved in each test. The geometry of the specimens includes three meshes with space trusses. The details of the geometry are shown in Figure 7a, while Figure $7 \mathrm{~b}$ shows the steel truss before casting and Figure $7 \mathrm{c}$ the complete specimen placed into the compression-testing machine. In all specimens, the bars constituting the upper chords are made of B450C steel. The diagonals of the truss are made of B450C ribbed steel in the case of specimens B12 and B14, and S355 smooth steel for specimens S12 and S14. The bottom chord is constituted by a steel plate of $6 \mathrm{~mm}$ made up of S355 steel. The concrete has an average cubic compressive strength of $42.6 \mathrm{~N} / \mathrm{mm}^{2}$. In specimens with identity tag S14 the welds between the initial and end diagonals and the base plate are removed. In almost all cases the collapse of the specimens was due to failure of the concrete, but sometimes failure of the welding also occurred. Figure 8 shows the load-displacement curves obtained from the Linear Variable Displacement Transducer (LVDT) measurements for each test representative of the specimens having all welds. The LVDTs were placed on the upper front side of the specimen (LVDT As and Ad) and next to one welding (LVDT Ps). In Figure 9 the deformed shape of the steel truss at the end of the test for specimen B12_2 is reported.

Table 2. Features of specimens tested by Aiello [5].

\begin{tabular}{|c|c|c|c|c|}
\hline ID & $\varphi_{\mathrm{w}}$ & $\varphi_{\mathrm{uc}}$ & $\mathbf{P}_{\mathbf{u}}(\mathbf{k N})$ & Failure \\
\hline S12_1 & \multirow{2}{*}{$\begin{array}{l}\text { S355 } \\
2 \varphi 12\end{array}$} & \multirow{2}{*}{$\begin{array}{c}\text { B450C } \\
1 \varphi 18\end{array}$} & 817.1 & \multirow{2}{*}{ concrete } \\
\hline S12_2 & & & 842.1 & \\
\hline S14_2 & \multirow{3}{*}{$\begin{array}{l}\text { S355 } \\
2 \varphi 14\end{array}$} & \multirow{3}{*}{$\begin{array}{c}\text { B } 450 \mathrm{C} \\
1 \varphi 18\end{array}$} & 787.1 & concrete \\
\hline S14_3 & & & 808.1 & concrete \\
\hline S14_4 & & & 861.1 & welding \\
\hline B12_1 & \multirow{2}{*}{$\begin{array}{c}\text { B450C } \\
2 \varphi 12\end{array}$} & \multirow{2}{*}{$\begin{array}{c}\text { B450C } \\
1 \varphi 18\end{array}$} & 996.1 & concrete \\
\hline B12_2 & & & 1007.5 & welding \\
\hline B14_1 & $\begin{array}{c}\text { B } 450 \mathrm{C} \\
2 \varphi 14\end{array}$ & $\begin{array}{c}\text { B } 450 \mathrm{C} \\
1 \varphi 8\end{array}$ & 1139.0 & steel \\
\hline
\end{tabular}



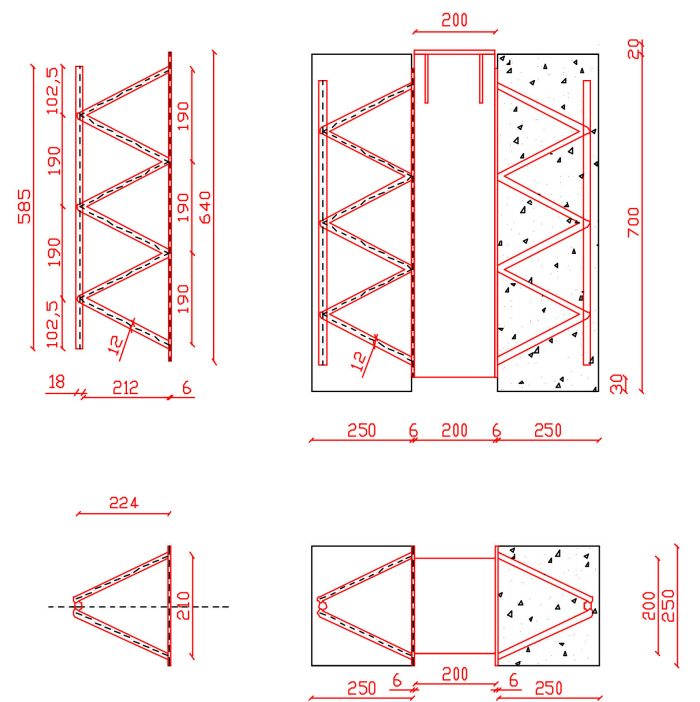

(a)

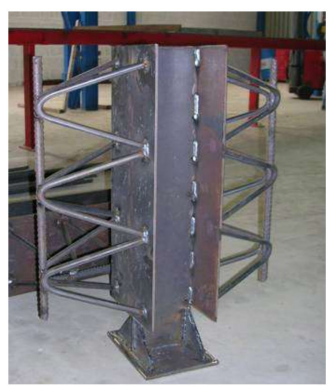

(b)

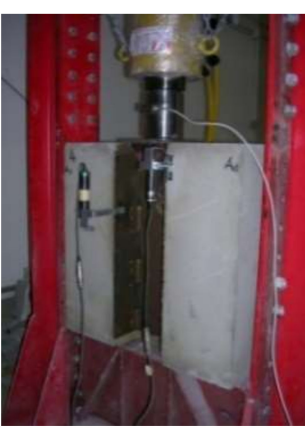

(c)

Figure 7. Push-out test in Phase II (Aiello). [5]: (a) geometry of specimens (dimensions in mm); (b) steel truss before casting; (c) specimen into the testing machine.

Badalamenti [13] and Badalamenti et al. [14] proved that, in a spatial truss too, correct sizing of the welding and proportioning of the (ribbed) web bars allows one to obtain a ductile collapse mechanism, in which the cracking caused by attainment of the tensile concrete strength is followed by a progressive transfer of tensile stresses from the concrete to the tensile web bars of steel trusses, and plate buckling is avoided. Ductile behaviour is ensured by activation of a plastic hinge at the connection of the tensile web rebars with the steel plate, and at the height corresponding to the concrete longitudinal crack in the compressed web bar.

They prepared three identical specimens, P1, P2 and P3 (see Figure 10a,b), where the trusses were made up of ribbed bars for reinforced concrete. The web bars had a diameter of $12 \mathrm{~mm}$, the upper chord was made up of three bars of $16 \mathrm{~mm}$ diameter and the bottom plate was constituted by a plate of $5 \mathrm{~mm}$. The bars were made with steel having nominal yielding strength equal to $450 \mathrm{~N} / \mathrm{mm}^{2}$ (B450C) while the base plate was made of S355 class steel. The concrete had a cylindrical resistance equal to $27.77 \mathrm{~N} / \mathrm{mm}^{2}$. In order to evaluate the stress in the web bars electric strain gauges were placed before concrete casting as shown in Figure 10c,d. After curing and maturation, in all specimens two other strain gauges were also placed on the steel plate on two sides of the truss bottom joint, in order to evaluate the stress transfer in the truss joint.

In all the tests, the ultimate loads obtained were very similar, with a mean value of $1104.7 \mathrm{kN}$, and specimen collapse was due to concrete failure. Specifically, the maximum load values recorded for specimens P1 and P2 were equal to $1051.6 \mathrm{kN}$ and $1004.9 \mathrm{kN}$ respectively while for specimen P3 a higher value was achieved, equal to $1257.5 \mathrm{kN}$. 
Figure 11 shows the load-displacement curves for the three tests considering the displacement values recorded by the testing machine. During the load history, appreciable cracks began to appear at a load value of $80 \%$ of the maximum load; they propagated until the maximum load, corresponding to the maximum concrete tensile strength, was achieved. In the descending branches the curves showed the progressive strength reduction that during the test was associated with a typical noise of breaking of metallic parts. It can be observed that the specimens exhibited a somewhat ductile branch to which there corresponded a rapid increase in vertical cracking of the concrete; the configuration of specimen $\mathrm{P} 1$ at the end of the test can be observed in the pictures reported in Figure 11. Specifically, in Figure 11b side views of the specimen P1 are shown, while in Figure 11c a view of the top face of the specimen is represented (a similar failure type was observed for the two other specimens). For all specimens, failure was due to achievement of the tensile strength in the concrete with formation of large amplitude cracks in the longitudinal direction of the specimen. Cracking caused progressive transfer of tensile stresses from the concrete to the tensile web bars of the steel trusses. The latter underwent large plastic strains near the connection to the plate, as was seen after removing the concrete from the specimen. In particular, by analyzing the pictures in Figure 12, which refer to specimen P1, it emerges that the compressed bars exhibited large deformations at a distance of about $50 \mathrm{~mm}$ from the plate, presumably corresponding to the longitudinal crack. A progressive reduction in the strength of the specimen appears, corresponding to the progressive rupture of the tensile web bars next to the plate. In all three tests, the welding remained undamaged.

S12_1

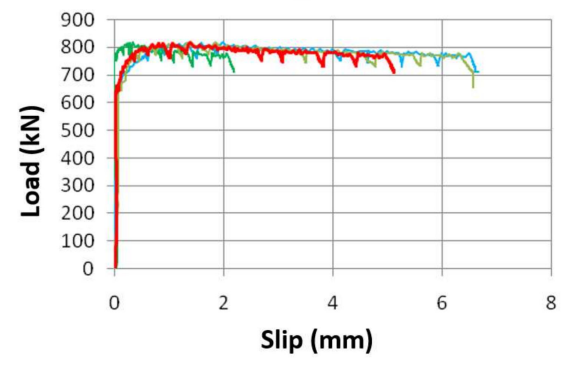

(a)

B12_1

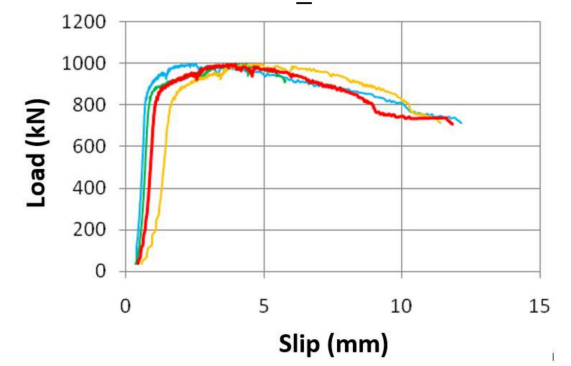

(c)

B14_1

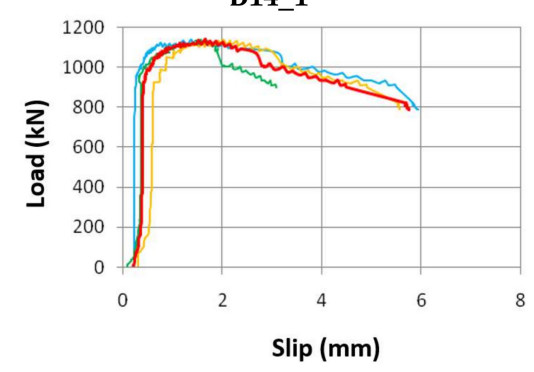

(e)

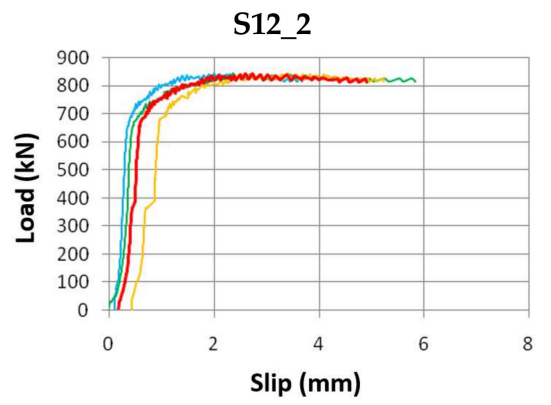

(b)

B12_2

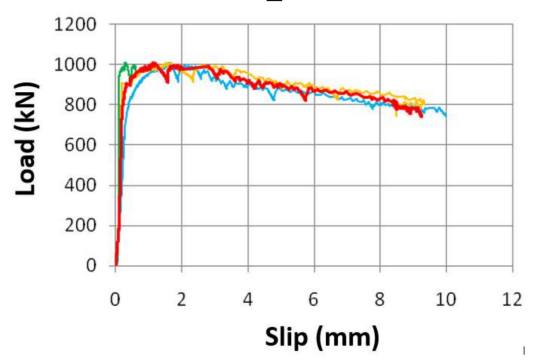

(d)

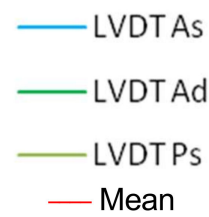

Figure 8. Load-displacement curves in push-out tests, by Aiello [5]: (a) specimen S12_1; (b) specimen S12_2; (c) specimen B12_1; (d) specimen B12_2; (e) specimen B14_1. 


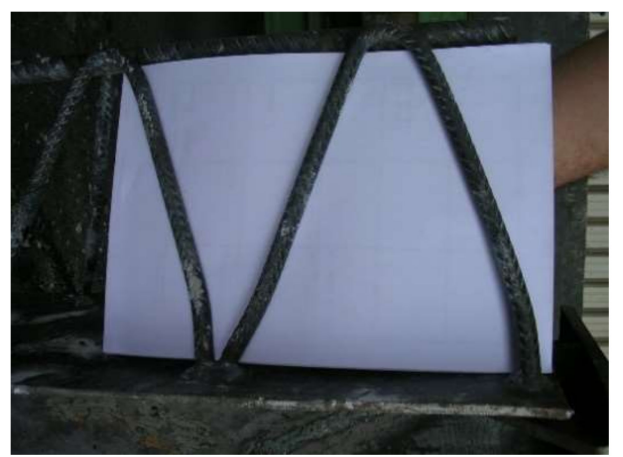

Figure 9. Deformed shape of the steel truss at the end of test B12_2 (Aiello) [5].
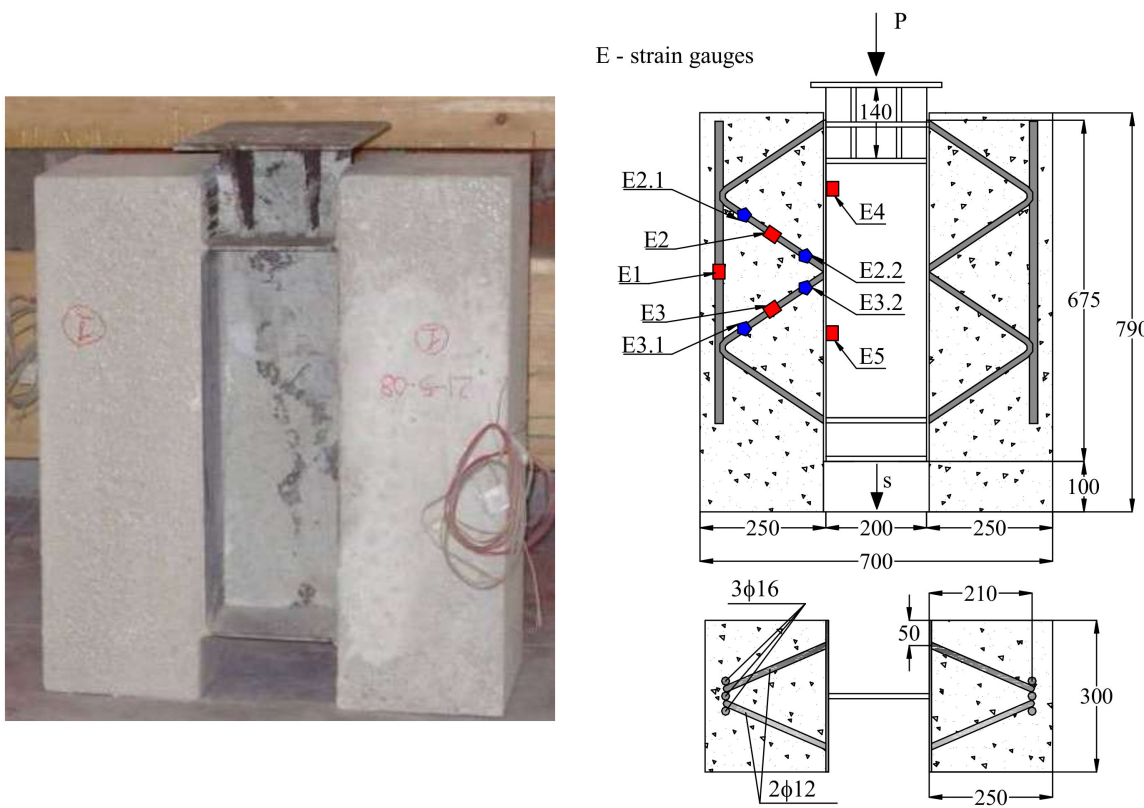

(a)

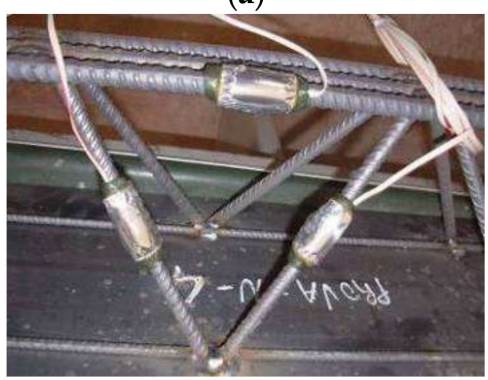

(b)

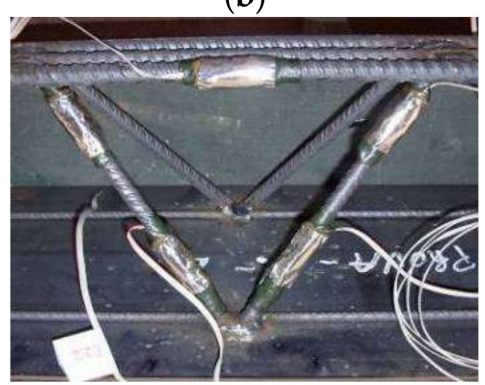

(d)

Figure 10. Specimen for push-out test in Phase II: (a) photo of a specimen; (b) geometry and instrumentation (dimensions in millimeters); (c) strain gauges in specimens P1 and P2; (d) strain gauges in specimen P3 (Badalamenti) [13]. 


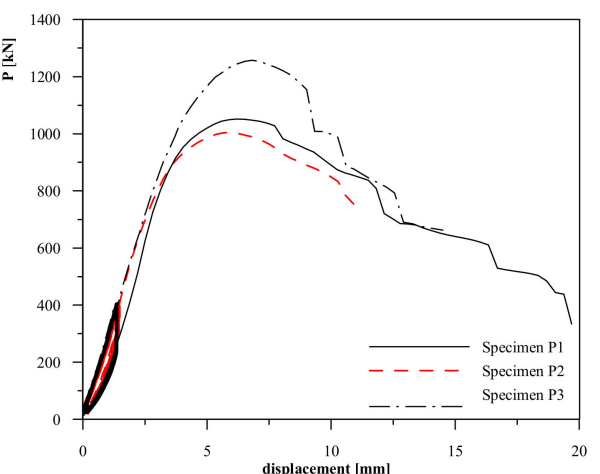

(a)

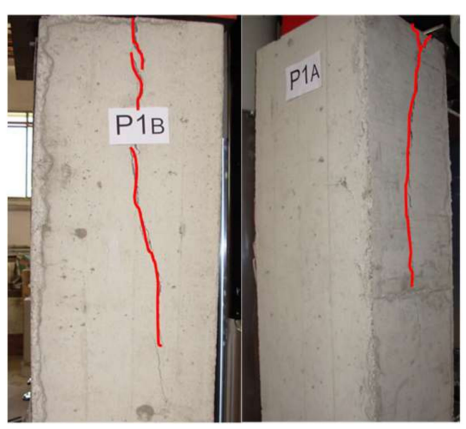

(b)

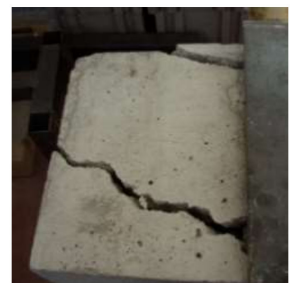

(c)

Figure 11. Push-out test in phase II (Badalamenti) [14]: (a). Load-displacement curves; (b) lateral view of specimen P1 at failure; (c) top view.

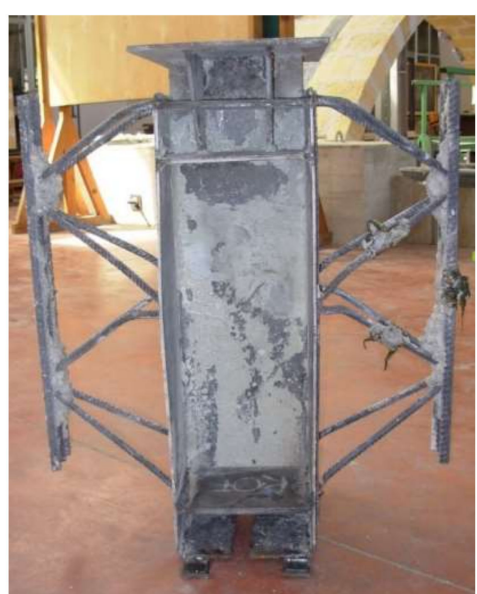

(a)

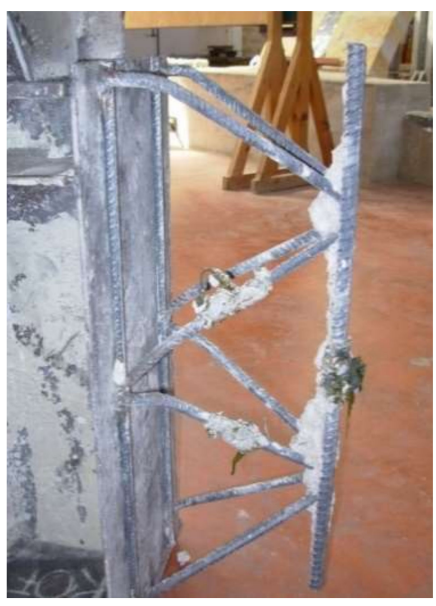

(b)

Figure 12. Deformed steel truss of specimen P1 at the end of the test (Badalamenti) [14]: (a) overall view; (b) zoom of deformed bars.

Finally, it is noteworthy that recently analytical and experimental investigation on HSTCBs were developed [11,12]. In the former study, evaluation of the shear resistance of the connection between bottom steel plate and concrete core through the diagonal bars of the truss was focused on, developing a mechanical model. In [12], the results of laboratory tests conducted on six specimens of two beam typologies, namely slab thick and full thick full-size HSTCBs, subjected to four-point bending, with variation in the shear span, are reported. The tests were designed in order to investigate the element resistance associated with three typical failure modes that can occur in HSTCBs, namely flexural, shear and connection failure. Analytical formulations for calculation of resistance derived from the available literature and technical codes were utilized to assess the failure modes of each beam and load configuration. Finally, the transfer length necessary to ensure the full strength of the connection were assessed. Both the two models will be presented in the following sections.

However, it has to be stressed that almost all the experimental investigations, and the derived analytical models concern HSTCBs with bottom chord made up of steel plate, while there is a lack of knowledge on the behavior of beams with precast prestressed concrete bottom chord.

\subsection{Analytical Models for Stress Transfer Mechanisms between Steel and Concrete}

In the literature, there are only a few models attempting to investigate the stress transfer mechanisms between steel lattice and surrounding concrete in HSTCBs. 
Tullini and Menghini [7] modeled the influence of the stiffness, strength and ductility of the connection on the overall behavior of the HSTCB. In their model, the hybrid beam was considered as a conventional steel-concrete composite beam with deformable shear connection provided by the web bars of the steel lattice welded to the steel plate at the bottom chord. Consequently, the behavior of the connection was reproduced by means of the kinematical model proposed in [30] assuming linear variation of the deformations within the layers represented by the concrete and the steel plate, and that the slip between the two elements can occur without vertical separation at their interface. Consequently, a nonlinear finite element formulation was derived in order to evaluate the ultimate bending strength of the hybrid beam. More precisely, once a polynomial law of the displacement field is assumed according to Amadio and Fragiacomo [31], a closed-form expression of the slip for the linear elastic behavior of a uniformly loaded simply supported beam was derived in order to characterize the response of hybrid beams with non-ductile shear connections. The authors stress that the hypothesis of linear elastic behavior of steel and concrete is a realistic one for technical design, when the ultimate limit state is governed by the premature crisis of the shear connection. They also derived a closed form expression of the ultimate flexural strength of a beam characterized by an elastic-perfectly plastic connection having constant stiffness along the beam axis.

In Colajanni et al. [10] attention was focused on the strength evaluation of the shear connection. Numerical models able to reproduce the results of the push-out test were developed, and an analytical relation able to reproduce both experimental and Finite Element (FE) results was proposed. The analytical model was refined in [11], where a design equation capable of assessing the ultimate action that can be transferred from the concrete core to the steel plate of the beam through the web bars of the lattice was derived. The efficiency of the formulation was proved by means of favorable comparison with numerical prediction by FEM and push-out test results.

In [10] a three-dimensional nonlinear FE model was developed. The constitutive relationship of the steel composing the plates and the rebars was modeled by means of a quadri-linear law, while the concrete behavior was defined by means of a Concrete Damaged Plasticity (CDP) model, suitable for modeling concrete and brittle materials. The CDP model uses the concept of isotropic damaged elasticity in combination with isotropic tensile and compressive plasticity to represent the inelastic behavior of concrete. It makes use of the yield function, which is able to account for different evolutions of strength under tension and compression. CDP is able to properly account for the concrete confinement effect and it assumes that the main two failure mechanisms are tensile cracking and compressive crushing. In order to accurately grasp the complicated dowel and bond phenomena arising at the steel-concrete interface, a 3D solid model was used to account for the actual contact surfaces between the truss and the concrete. The behavior of HSTCBs constituted by either deformed or smooth steel diagonal bars was investigated, and four models for the steel-concrete interface were analyzed. Sensitivity of the response to the size of the mesh was analyzed.

In [11] the Authors highlight that the connection behavior is governed by the relative strength between steel lattice, concrete core, and welds, which are determined by the interaction among different mechanisms, such as lateral confinement of concrete, nonlinear behavior of materials, contacts and detachment phenomena. Although different collapse mechanisms could be activated depending on the hierarchy of strength between them, the weld failure can easily be avoided by prope sizing. In his circumstance, the geometrical and mechanical characteristics of the more widespread typologies ensure that the most frequent collapse mechanism is due to activation of two plastic hinges formed on each of the web bars of the lattice. They are placed in the regions near to the plate and in another section along the diagonal rebar longitudinal axis, like what occurs in dowels and piles in cohesive soils. Thus, the authors derived a model inspired by models already existing in the technical literature concerning the abovementioned systems [32-35]. On the basis of the mechanisms reported in Broms [32] and Vintzeleou and Tassios [35], several noteworthy parameters are identified for extending the model to estimation of the steel dowel/pile strength to inclined steel rebar pushed against concrete. Primarily, the effect of the amount of lateral confinement of the steel rebar, and secondly the plastic 
hinge length arising on the inclined rebar, are investigated. Furthermore, unlike most of the approaches present in models available in the literature, this formulation takes into account the $M-N-V$ internal force interaction in evaluating the ultimate strength domain of the diagonal web rebar.

To this aim, the authors selected the collapse mechanism shown in Figure 13, where the following most significant parameters can be recognized:

1. dowel leaning (i.e., leaning of the web bar of the lattice) represented by means of the angle $\alpha$ formed along the inclined plane of the truss. The angle $\alpha$ is evaluated according to the geometrical dimensions of the lattice, as follows:

$$
\alpha=\arccos \left(\frac{0.5 s}{\sqrt{0.25 s^{2}+d^{2}+0.25 b^{2}}}\right)
$$

in which $s, b$ and $d$ are the lattice spacing, width and depth, respectively;

2. bearing stress of concrete $f_{b}=\psi f_{c}$, which depends on the width of the lateral concrete covers $c_{1}$ and $c_{2}$ as defined in the formulation by Vintzeleou and Tassios [35], where a correction coefficient $\delta=(\psi / 3)^{0.5}$ fluctuating in the range $0.60-1.30$ can be evaluated as follows:

$$
\begin{array}{cc}
\delta(I)=0.6+\frac{c_{1}}{d_{b}}\left(0.027 \frac{c_{2}}{d_{b}}+0.1\right) & \text { for } 0 \leq \frac{c_{1}}{d_{b}} \leq 3 \text { and } 0 \leq \frac{c_{2}}{d_{b}} \leq 5 \\
\delta(I I)=0.9+0.08 \frac{c_{2}}{d_{b}} & \text { for } \frac{c_{1}}{d_{b}} \geq 3 \text { and } 0 \leq \frac{c_{2}}{d_{b}} \leq 5 \\
\delta(I I I)=0.6+0.233 \frac{c_{1}}{d_{b}} & \text { for } 0 \leq \frac{c_{1}}{d_{b}} \leq 3 \text { and } \frac{c_{2}}{d_{b}} \geq 5 \\
\delta(I V)=1.3 & \text { for } \frac{c_{1}}{d_{b}} \geq 3 \text { and } \frac{c_{2}}{d_{b}} \geq 5
\end{array}
$$

Thus, the coefficient value $\psi=5$ that rules the value of the plastic strength of the concrete can be assumed when the concrete is fully confined (i.e., $c_{1} / d_{b} \geq 3$ and $c_{2} / d_{b} \geq 5$ ), while $\psi=(\delta \sqrt{ } 3)^{2}$ when the confinement effect depends on the concrete cover;

3. the boundary condition of the head of the dowel: the dowel is modeled as clamped to the steel plate of the lattice so that at failure two plastic hinges are activated. The distance between the two plastic hinges is $\left(L_{\text {eff }}-a\right), L_{\text {eff }}$ being the effective length of the web rebar and $a$ the length of the plastic hinge located near the steel plate;

4. the bending moment that activates the plastic hinges when the shear force $V$ vanishes is evaluated according to the bending moment $M$-axial force $N$ interaction domain assumed in Millard and Johnson (1984) [36]

$$
M_{p l}=\frac{d_{b}^{3}}{6} f_{y}\left(1-N^{2} /\left(\pi \frac{d_{b}^{2}}{4} f_{y}\right)^{2}\right)
$$

5. the shear-normal stress interaction $M-N-V$ is considered according to Eurocode 3 [37] indications in which shear reduces the amplitude of axial force-bending moment interaction domain by tuning the steel ultimate strength by means of a coefficient $(1-\rho)$. $A_{s w}$ and $f_{u}$ being the cross-section area and the ultimate strength of the steel of the web bar, the reduction coefficient can be evaluated as $\rho=\left(2 V / V_{R u}-1\right)^{2}$ for $V \geq 0.5 V_{R u}$, where $V_{R u}=0.8 f_{u} A_{s w}$.

According to the structural system shown in Figure 13 the equilibrium equations read as follows:

$$
\begin{gathered}
V \cos \alpha=N \\
V \sin \alpha-f_{b} \cdot d_{b} \cdot a=f_{b} \cdot d_{b} \cdot\left(L_{e f f}-a\right) \\
2 M_{p l}+f_{b} \cdot d_{b} \cdot 0.5\left(L_{e f f}-a\right)^{2}=\left(V \sin \alpha-f_{b} \cdot d_{b} \cdot a\right)\left(L_{e f f}-a\right)
\end{gathered}
$$




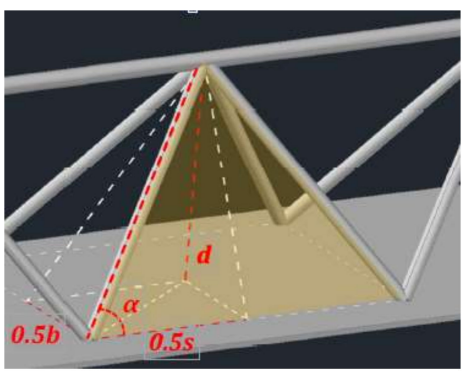

(a)

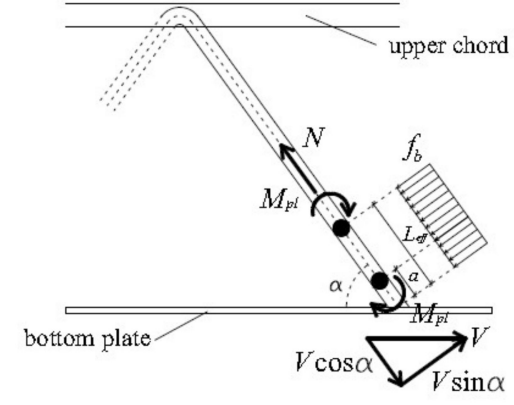

(b)

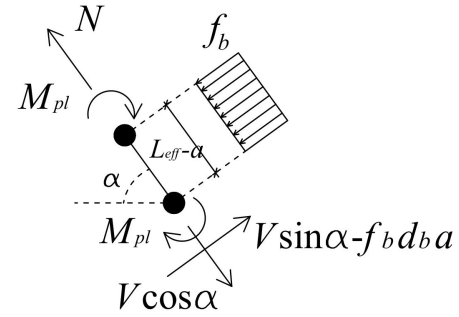

(c)

Figure 13. Selected collapse mechanism [11]: (a) spatial view; (b) structural scheme; (c) force equilibrium.

where the plastic flexural moment $M_{p l}$ is given by Equation (3) in which Equation (4) is taken into account, meaning it depends on the dowel force $V$. The authors stress that the symbol $V$ used in Equations (4)-(6) does not provide the shear action of the beam, but it provides the value of the shear action that can be transferred from the concrete core to the steel plate through the bars of the lattice. Likewise, the axial force $\mathrm{N}$ on the web bar has to be calculated by means of the Morsch truss.

Once the value of $N$ is explicated from Equation (4) and that of $M_{p l}$ from Equation (6), and they are substituted in Equation (5), the following implicit relationship for the shear strength can be derived:

$$
V^{2}\left(\frac{\sin ^{2} \alpha}{2 f_{b} d_{b}}+\frac{16 \cos ^{2} \alpha}{3 \pi^{2} d_{b} f_{y}\left(1-\left(\frac{10 V}{f_{u} \pi d_{b}^{2}}-1\right)^{2}\right)}\right)-V \cdot a \cdot \sin \alpha-\left(\frac{d_{b}^{3}}{3} f_{y}\left(1-\left(\frac{10 V}{f_{u} \pi d_{b}^{2}}-1\right)^{2}\right)-\frac{f_{b} d_{b} a^{2}}{2}\right)=0
$$

where $f_{b}=\psi f_{c}$, and the steel yielding strength of the steel rebar in Equation (7) is reduced according to the interaction with the shear force ( $M-N-V$ interaction) suggested by the Eurocode 3 (CEN 2005) [37] prescriptions. A simpler direct expression of the dowel shear strength can be derived if the $M-N-V$ interaction is neglected, since from Equation (7) the following relation for the dowel strength is derived:

$$
V^{2}\left(\frac{\sin ^{2} \alpha}{2 f_{b} d_{b}}+\frac{16 \cos ^{2} \alpha}{3 \pi^{2} f_{y} d_{b}}\right)-V a \sin \alpha-\left(\frac{d_{b}^{3}}{3} f_{y}-\frac{f_{b} d_{b} a^{2}}{2}\right)=0
$$

Moreover, if both the internal force interaction is ignored and the distance $a$ of the plastic hinge from the steel plate is neglected, the following simpler analytical expression for the dowel strength $V$, useful for practical design purposes, is derived:

$$
V=\frac{d_{b}^{2} \sqrt{2 f_{y} f_{b}}}{\sqrt{3 \sin ^{2} \alpha+\frac{32 f_{b}}{\pi^{2} f_{y}} \cos ^{2} \alpha}}
$$

Hence, the connection strength can be evaluated according to three proposed expressions, called in the following sections model $A$, model $B$, and model C:

- model $A$ delivers the dowel strength provided by a single web rebar of the HSTCB lattice, formulated to take into account the actual plastic hinge length $a$ and by assessing the effect of actual the level of concrete confinement by means of the coefficients $\psi$, and $\delta$, the latter expressed by Equation (2). According to this model, the evaluation of $V$ requires that Equation (5) is solved, retaining the $M-N-V$ interaction effects governed by the Eurocode 3 prescriptions.

- $\quad$ model $B$, where the $M-N-V$ interaction effect only is neglected, delivers the analytical expression of the value of the shear strength $V$-dowel strength connection in Equation (8). 
- $\quad$ model $C$, where both the $M-N-V$ interaction effects and the distance of the plastic hinge from the steel plate are neglected (i.e., $\rho=1$ and $a=0$ are assumed) and the maximum amount of concrete confinement is retained (i.e., assuming $\psi=5$ ). According to the abovementioned simplification, an analytical expression of the value of connection shear strength $V$ is provided in the closed form by Equation (9).

The authors provide a favorable validation of the models by comparison with numerical FEM and experimental results available in the technical literature.

In sum, the above presented models allow evaluation of both the strength of the steel truss-to concrete connection, and the overall behavior of HSTCBs with bottom chord made up of steel plate. However, it has to be stressed that, often in the construction practice, rebars are added and welded to the bottom chord steel plate, in order to increase the capacity of the connection, and increase the shear strength exploiting the dowel action of the system obtained by the collaboration of the added rebars and the steel plate. None of the experiments and models in the literature have analyzed the effect of this technical solution on the connection capacity.

\section{Shear Strength}

\subsection{Experimental Results}

A large number of shear tests on HSTCBs were carried out between 1987 and 1990 by the Italian industry CSP. A typical specimen geometry and load condition (simply supported beam subjected to a concentrated load applied at the midspan) of the tested beam is represented in Figure 14a. Figure 14b shows typical shear failure that occurred in the tested beams and in Figure 14c the detail of the crack pattern is represented. Figure $14 \mathrm{~d}$ shows the specimen at the end of the test, focusing on the position of the failed concrete strut with respect to the web steel bars. It can also be observed that spalling of the concrete corresponding to the inferior face of the beam is prevented by the presence of the bottom steel plate.

The results pointed out that the shear resistance mechanisms are different than those observed in similar R.C. beams, and the maximum loads achieved was higher in most cases. It was noted that the steel truss and the bottom plate make a significant contribution to the shear overstrength of the system. However, the behavior of each beam was highly dependent on the typology geometric of the truss, constituted by inclined or vertical compressed web bars, and by the finishing of the surface (smooth or ribbed) of the web bars. Izzo et al. [38] stressed that the hypothesis of perfect bond between the steel reinforcement and the concrete matrix (usual in models for R.C. beams) is not realistic, especially for a beam made of smooth steel instead of ribbed steel bars. Thus, he stressed that: understanding of the stress transfer mechanisms between the steel members and the concrete is an aspect of paramount importance since the connection has to be provided almost solely by the steel truss; and that, considering the limitation of the bond stress, the arch effect that is activated in the shear failure mechanism of HSTCBs, is a preeminent contribution, which leads to an increased risk of failure due to crushing of the compressed concrete strut.

More recently, another experimental campaign on shear failure on HSTCBs was carried out by Chisari and Amadio [16]. They analyzed the role of added bottom rebars welded to the plate and rebar surface finishing (smooth or ribbed). 


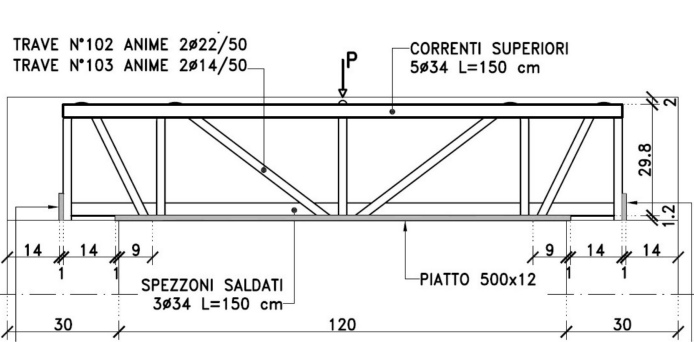

(a)

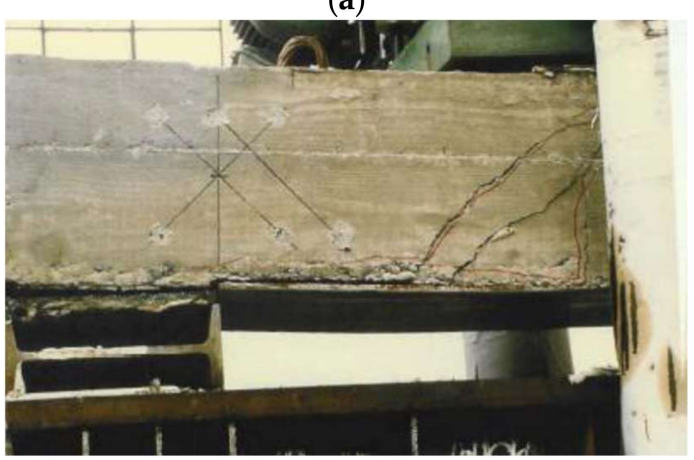

(c)

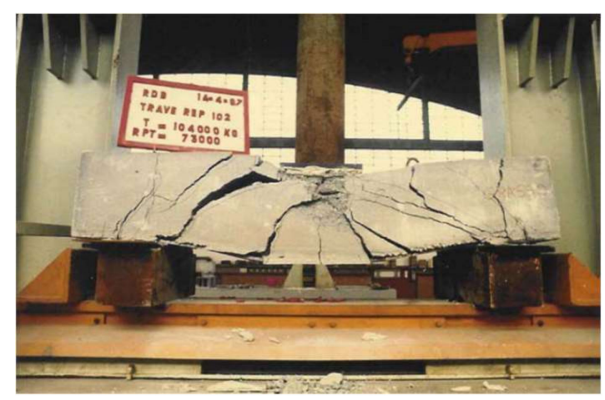

(b)

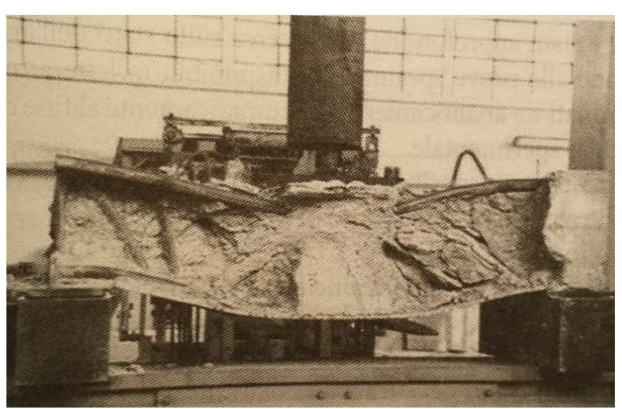

(d)

Figure 14. (a) Specimen for shear test; (b) shear failure; (c). Crack pattern of Hybrid Steel Trussed Concrete Beam (HSTCB) with separation of the lower steel plate; (d) specimen at the end of the test with no spalling of the concrete thanks to the presence of the lower steel plate.

Three-point bending tests were carried out on three types of specimens, all characterized by the presence of a bottom steel plate. The cross-sections of the specimens are shown in Figure 15: they differ for the number of bottom-added rebars welded to the steel plate, zero (Acc0), three (Acc3) or five rebars (Acc5) respectively. The added rebars have the aim of increasing the bond between the bottom steel plate and the concrete, and provide dowel action. Furthermore, it is worth noting that, for each cross-section, three different specimens were manufactured, giving cases where the upper chord and the diagonal bars were both ribbed (cn-an), the upper chord was ribbed while the web bars were smooth (cn-al), and the upper chord was smooth and the diagonals were ribbed (cl-an).
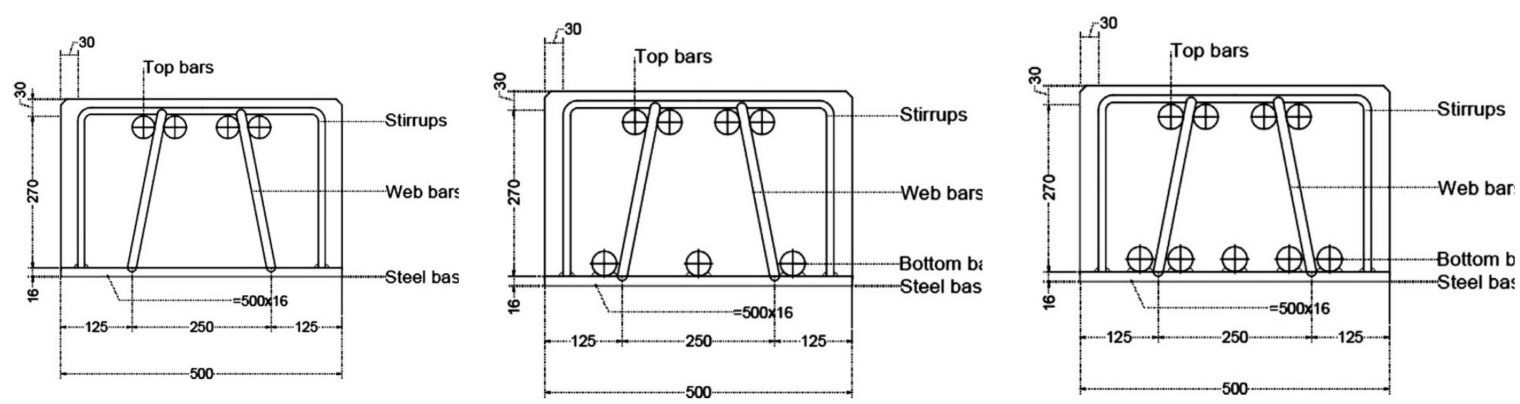

Figure 15. Cross-sections of the three typologies of tested beams (Chisari and Amadio [16]).

The beams were simply supported at the ends and loaded with a concentrated force asymmetrically applied with respect to the midspan. The tests were performed in displacement control. The scheme of the geometry and the load condition is represented in Figure 16. 


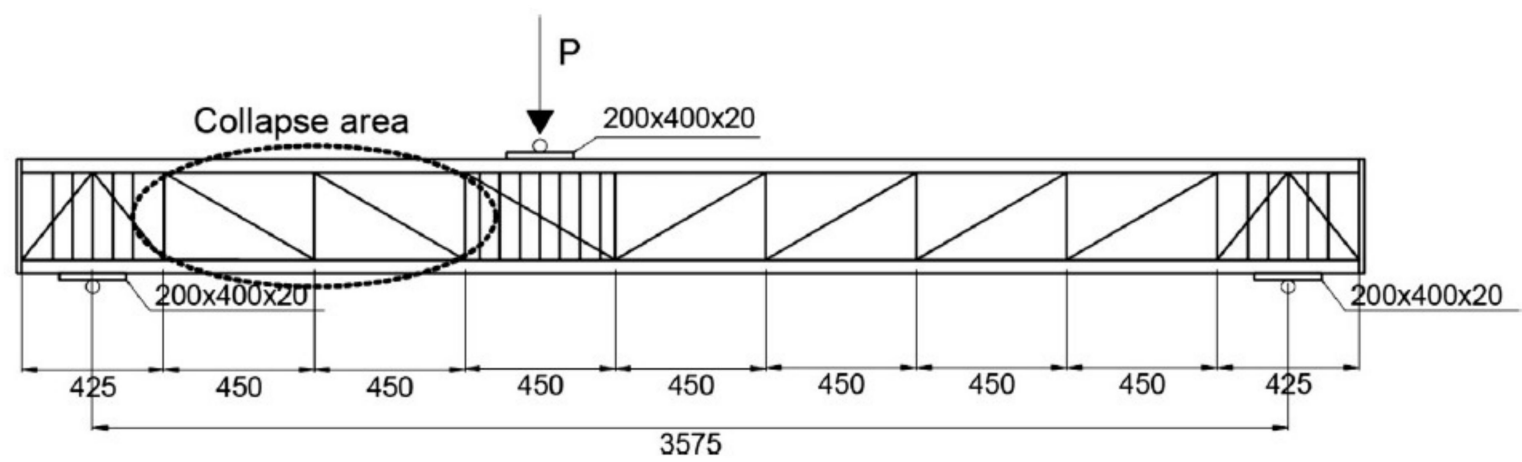

Figure 16. Geometry of the beam and load condition (Chisari and Amadio [16]).

The load-displacement curves showed that the three specimens without lower added rebars exhibited almost the same behavior with a maximum load of about $860 \mathrm{kN}$ (see Figure 17a). Concerning the specimens with three added rebars, the beam constituted by both ribbed upper chord and diagonal bars exhibited a higher peak load equal to $1080 \mathrm{kN}$, while the other two specimens achieved a maximum load of about $930 \mathrm{kN}$ (see Figure 17b). Finally, with reference to the third series of specimens made with five added inferior rebars, the beams exhibited almost the same behavior achieving a peak load whose value was in the range between $975 \mathrm{kN}$ and $1050 \mathrm{kN}$ (see Figure 17c). No welding failure was observed after removal of the concrete.

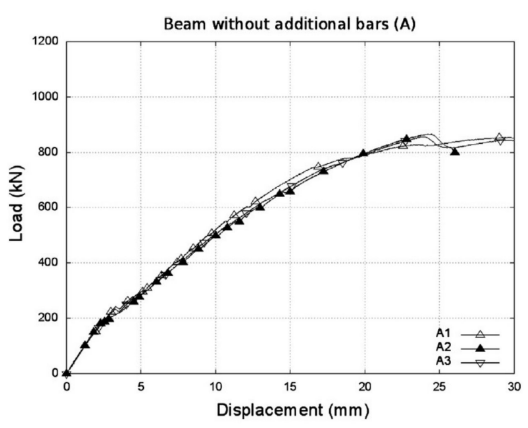

(a)

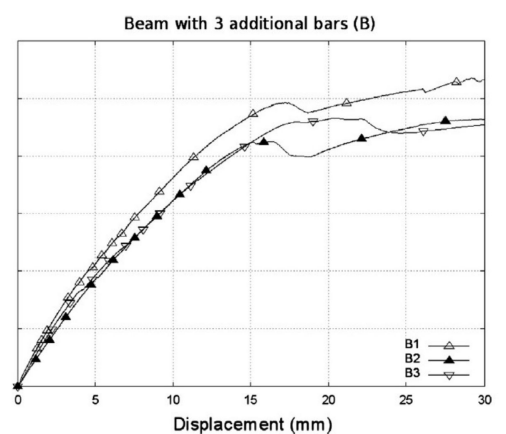

(b)

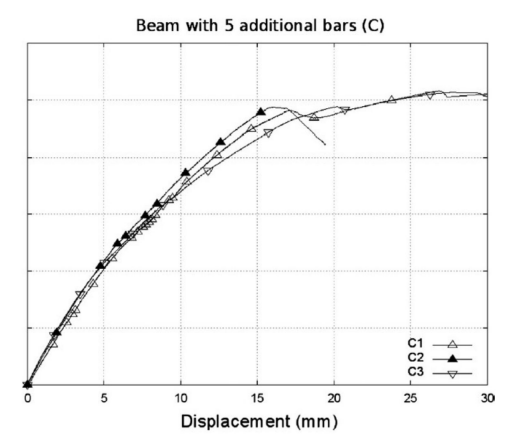

(c)

Figure 17. Load-displacement curves: (a) beams without lower rebars; (b) beams with three added lower rebars; (c) beams with five lower added rebars (Amadio et al. [16]).

The results proved that a very important role is played by the concrete-steel plate base bond, which cannot be assured only by connections and terminal plates. If it is partially also guaranteed by longitudinal bars welded to the base, full shear strength can be attained.

Recently, the outcomes of a test survey on shear critical HSTCB by means of three-point bending tests were published [20], investigating the effects of concrete compressive strength and load application direction. The experiments were performed on five HSTCB specimens divided into two series, and carried out applying symmetric loads. In detail, two series of specimens were tested. Series A was loaded in order to obtain a positive bending moment, with the bottom steel plate in tension. In series B, the specimens were placed upside-down, so that the steel plate was subjected to compression action and the longitudinal rebars of the lattice were in tension, representing a load condition in which the beam in an actual frame was subjected to negative bending moment and shear. The characteristic cross-section of the truss is displayed in Figure 18a: it contains three upper rebars of 16-mm diameter, a bottom steel plate $5 \mathrm{~mm}$ thick, and two web rebars of $12 \mathrm{~mm}$ diameter. The beam depth and width are $250 \mathrm{~mm}$ and $300 \mathrm{~mm}$ respectively. In the Series A beams, specimen A1 has 4 additional $16 \mathrm{~mm}$ diameter bars added at the top chord (Figure 18b), while specimens A2-1 and A2-2 have $16 \mathrm{~mm}$ diameter supplementary bars, 4 in the top chord and 2 on the bottom chord 
(Figure 18c). Lastly, the Series B beams, labeled as B1 and B2, have the same cross-section as specimen A1 (Figure 18b).

Figure 18d shows the longitudinal section of the beams, where the specimen is placed upside down, as in the Series B beams, and the load configuration. All specimens were loaded with a $600 \mathrm{~mm}$ shear span. The steel plate ends were bent, and welded at the top chord in order to avoid plate-to-concrete relative slip. The slip could have significantly influenced the failure mode, activating unrealistic behavior. In fact, in actual beams, the bottom plate is fixed at the beam-column joints by suitable devices designed to avoid slip activation. The top chord, web and additional rebar were made of steel type B450C, while for the bottom plate a smooth steel class S355 $\left(f_{y k}=355 \mathrm{MPa}\right)$ was utilized. Specimens A1 and B1 were cast with concrete having a mean compressive strength of 25.16 MPa (concrete type 1), while specimens A2-1 and A2-2 and B2 were cast with concrete having a mean compressive strength of $15.66 \mathrm{MPa}$ (concrete type 2).

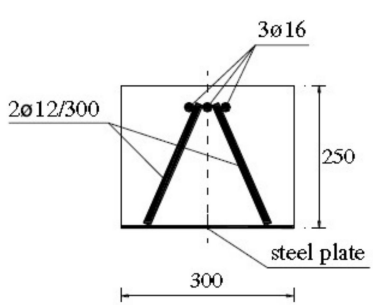

(a)

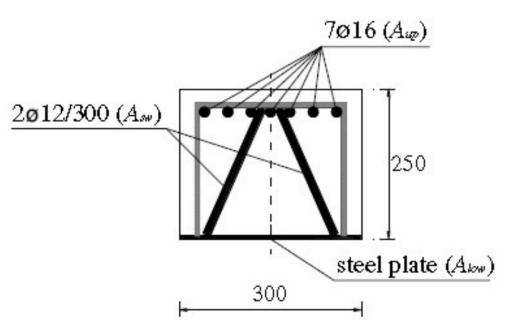

(b)

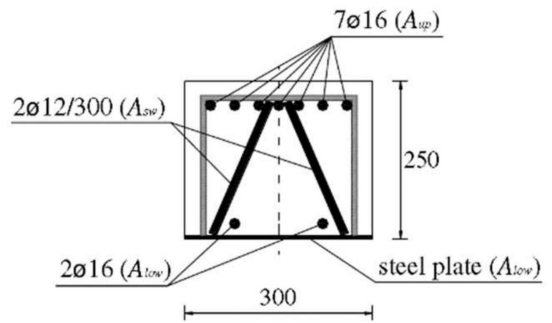

(c)

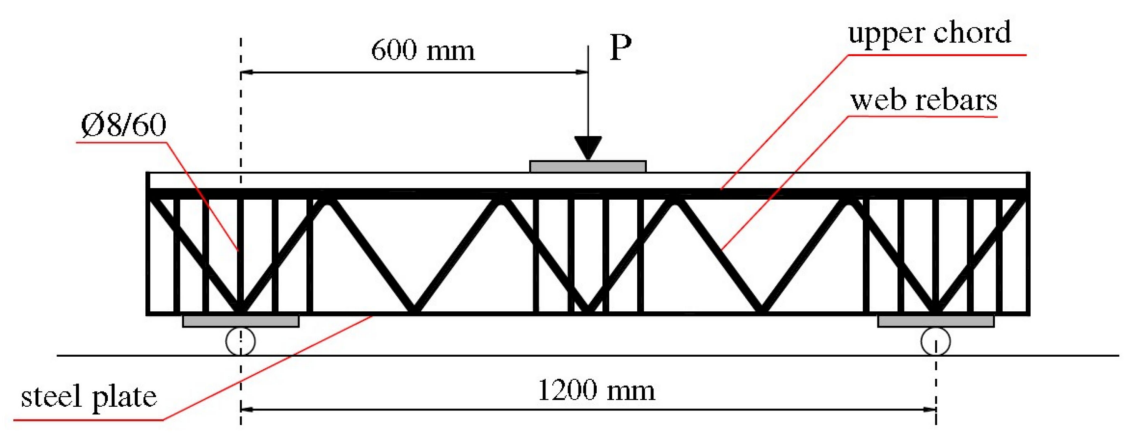

(d)

Figure 18. Dimensions of cross-section of tested specimens (mm); cross-section of: (a) truss; (b) specimens A1, B1, and B2; (c) specimens A2-1; (d) longitudinal section of a tested specimen and load configuration (series B) (Colajanni et al., [20]).

Figure 19a displays the load-displacement curve of the Series-A specimens (Positive Bending Moment). In detail, specimen A1 showed shear collapse at a deflection of $22.35 \mathrm{~mm}$ and a corresponding shear strength of $577.74 \mathrm{kN}$. During the loading process, the first vertical cracks appeared under the load application point at the load value of $190 \mathrm{kN}$, while at the load value of $320 \mathrm{kN}$ diagonal shear cracks began to appear. The specimen showed ductile behavior until the evolution of the main diagonal shear crack, which caused brittle shear failure. Conversely, samples A2-1 and A2-2. cast with weak concrete (Type 2), from the beginning exhibited evident brittle shear failure, attaining a load maximum value of $422.29 \mathrm{kN}$ and $461.29 \mathrm{kN}(27 \%$, and $20 \%$ smaller than that of Specimen A1). The behavior was characterized by partial detachment of the bottom steel plate from the concrete core. The collapse of the specimens was caused by failure of the compressed concrete strut, as shown in Figure 19b,c. Figure 20a displays the load-deflection curves of the series B samples. Sample B1, cast with the stronger type 1 concrete, exhibits a mixed flexure-shear collapse mechanism. It was characterized by quasi-ductile behavior, attaining the maximum load of $519.53 \mathrm{kN}$ and corresponding 
deflection of $8.99 \mathrm{~mm}$. Failure was attained with a residual strength and a corresponding deflection of about $380 \mathrm{KN}$ and $27 \mathrm{~mm}$. Sample B2, cast with weak type 2 concrete, exhibits a shear collapse mechanism characterized by more brittle behavior, shear strength of $335.94 \mathrm{kN}$ ( $54 \%$ smaller than that of specimen B1), and a corresponding deflection of $9.17 \mathrm{~mm}$. During the load process close to the peak load, a crack formed transversally at the bottom face of the specimen, and concrete crushing near the support came into play (see Figure 20b,c). The rebar of the chord of the lattice exerted dowel action, typical of a shear mechanism.

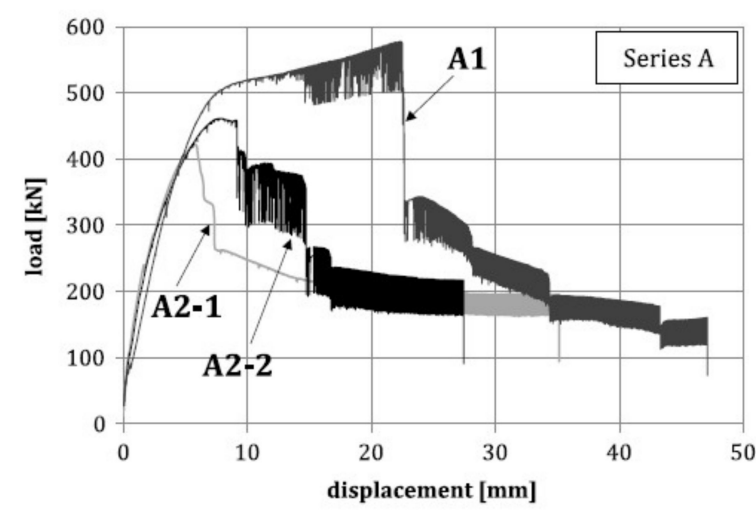

(a)

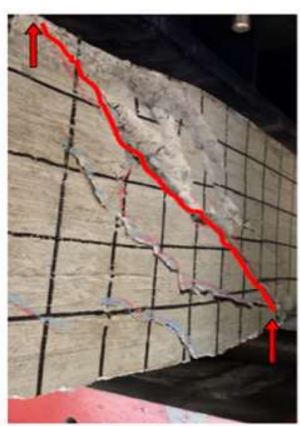

(b)

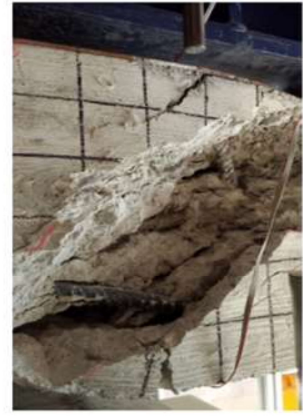

(c)

Figure 19. Series A: (a) load-deflection curves; (b) main diagonal shear crack (spec. A2-1); (c) "upper" chord (specimen placed upside-down) and tensile web bar of the truss across the diagonal crack (spec. A2-1).

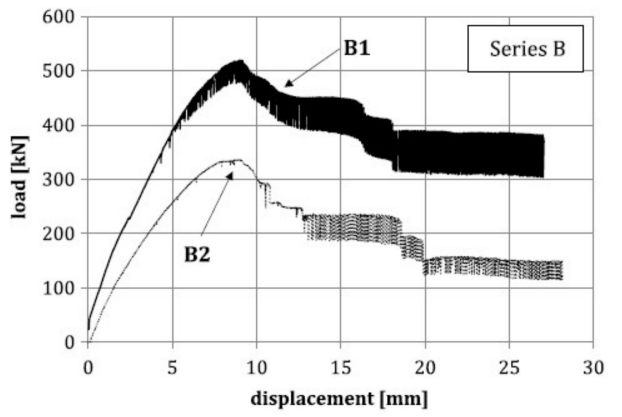

(a)

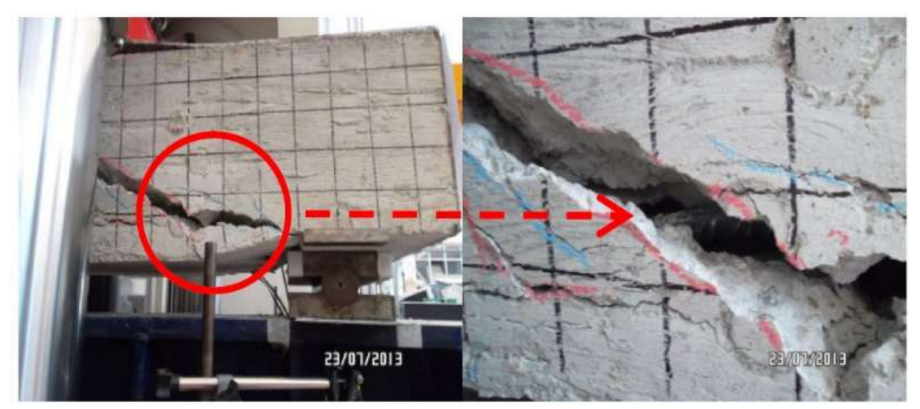

(b) (c)

Figure 20. Series B: (a) load-deflection curves; (b) main diagonal crack at the support (spec. B2); (c) detail of the dowel mechanism (spec B2).

The authors summarize the test results as follows: concerning all specimens loaded to induce positive bending moment (series A), the main diagonal shear crack came into play in the direction of the compressed concrete strut and grew progressively, while previously formed sub-vertical flexural cracks were almost stable. After attainment of the maximum load, initially a sub-horizontal branch of the curve was ensured by the residual strength of the steel members. When concrete compressive strength was attained, brittle shear failure arose, followed by a sudden drop in beam load capacity. The bottom steel plate locally disconnected from the concrete core.

Regarding the two samples subjected to negative bending moment (B1 and B2), the beam behavior was characterized by brittle failure in the case of weak concrete (sample B2), while it was more ductile for strong concrete (sample B1). The pattern and development of flexural and shear cracks were the same as for the specimens loaded with positive bending moment, with the addition of local crushing of the concrete close to the lateral supports. The steel plate buckled and separated from the concrete 
core. None of the welds, either between steel plate and web bar, or between web and top chord rebar, exhibited any damage.

\subsection{Mechanical Models for Shear Strength}

Aiming at assessing the shear strength of HSTCBs, different models are available in the literature, some of them consisting of relations derived for other beam typologies and suitably adapted to the typology considered, while others are derived on purpose for HSTCBs. Most of the former are also part of national and international codes. Specifically, the code relations here considered are those pertaining to former (EC2-92 [39]) and present (EC2-04 [40]) Eurocode 2, the American code ACI 318-08 [41], the Canadian code CAN-CSA 2004 [42], and the former and present Italian building code, D.M. 09-January-1996 [43] and D.M. 14-January-2008 [44], herein shortly denoted as DM-96 and DM-08 respectively. These relations were formulated for standard R.C. elements, and usually adapted to HSTCBs too. Recently, other researchers have formulated on purpose models for assessment of shear strength in HSTCBs. Among them, a first group of models are formulated in order to provide simple relations to be used for design of the beam (design-oriented models), (Amadio et al., [25], Chisari and Amadio [16]). Those of the second group require more complex procedures (analysis-oriented models), such as those of Monti and Petrone [18] and Campione, Colajanni and Monaco [19]. In the following sections, the models of the former group will be described in detail, and those of the latter group only summarized.

In reviewing design-oriented models suggested by the codes or by researchers, they are divided into two classes: namely additive models and truss models.

To the former class (additive models) the following models belong: EC2-92 [39], ACI 318-08 [41], the Canadian code CAN-CSA 2004 [42], the former Italian code DM-96 [43], along with the models derived by Chisari and Amadio [16] and Amadio et al. [25]. They evaluate the shear strength $V_{R}$ by adding the strength provided to the concrete, $V_{c}$, and the strength provided by the web reinforcement $V_{s w}$, namely

$$
V_{R}=V_{c}+V_{s w}
$$

therefore, they differ from each other for the way these two contributions are considered.

In EC2-92 [39] the share of the shear strength provided by the concrete is evaluated as:

$$
V_{c}=\left[\tau_{r d} k\left(1.2+40 \rho_{l}\right)+0.15 \sigma_{c p}\right] b_{w} d
$$

where $\tau_{r d}=0.25 f_{c t k 0.05} / \gamma_{c}$ is the concrete shear strength, $k=1.6-d$ a size effect coefficient, $\rho_{l}$ the longitudinal reinforcement geometric ratio, and $\sigma_{c p}$ the compressive stress (if present), $b_{w}$ and $d$ the width and the effective depth of the beam, respectively.

Moreover, the share provided to the web reinforcement is estimated as:

$$
V_{s w}=0.9 d \frac{A_{s w}}{s} f_{y w}(1+\cot \alpha) \sin \alpha
$$

$A_{s w}$ being the web shear reinforcement area, $f_{y w}$ the steel yielding strength, $\alpha$ and $s$ the leaning and the spacing of the web reinforcement.

The Italian building code of 1996, DM-96 [43], uses an analogous additive model, where the concrete strength share is evaluated as:

$$
V_{c}=0.6 f_{c t d} b_{w} d \delta
$$

$f_{c t d}$ being the concrete tensile strength and $\delta$ a coefficient (equal to 1 for pure bending) that tunes the contribution of the compressed concrete above the neutral axis as a function of compression stress acting along the beam axis. The share of web reinforcement can be evaluated according to Equation (12). 
In ACI 318M-08 [41] also, the shear strength of an R.C. beam is evaluated by the additive model. Specifically, the expression of $V_{c}$ is:

$$
V_{c}=\left(0.16 \lambda \sqrt{f_{c}^{\prime}}+17 \frac{A_{s}}{b_{w} d} \frac{V_{u} d}{M_{u}}\right) b_{w} d \leq 0.29 \sqrt{f_{c}^{\prime}} b_{w} d \quad f_{c}^{\prime} \text { in MPa }
$$

while $V_{s w}$ can again be evaluated according to Equation (12).

The Canadian Standard Code [42] provides the following equations for the concrete shear strength and web transverse reinforcement shares, respectively:

$$
\begin{gathered}
V_{c}=\phi_{c} \lambda \beta \sqrt{f_{c}^{\prime}} b_{w} d \quad f_{c}^{\prime} \text { in MPa } \\
V_{s w}=\phi_{s} \frac{A_{s w}}{s} f_{y w} d \cot \vartheta
\end{gathered}
$$

where $\phi_{c}$ and $\phi_{s}$ are safety factors for concrete and steel, $\lambda$ is a coefficient equal to 1 in the case of normal weight concrete, and $\beta$ and $\vartheta$ can be evaluated according to Bentz and Collins (2006) [45] as follows:

$$
\begin{gathered}
\beta=0.40 /\left(1+1500 \frac{f_{y}}{2 E_{s}}\right) \\
\vartheta=29^{\circ}+7000 \frac{f_{y}}{2 E_{s}}
\end{gathered}
$$

The model proposed by Amadio et al. [25] was formulated on purpose for the HSTCB characterized by the addition of some steel angles. Therefore, the equation for shear strength evaluation comprises three shares instead of two, and reads as follows:

$$
V_{R}=V_{c}+V_{s w}+V_{\text {ang }}
$$

$V_{\text {ang }}$ being the shear strength provided by the steel angles. The equation recalled for evaluating $V_{c}$ is that prescribed in the current Italian building code [44] for the shear strength of elements without shear reinforcement, similar to Equation (13):

$$
V_{c}=\left[\frac{0.18}{\gamma_{c}} k\left(100 \rho_{l} f_{c}^{\prime}\right)^{1 / 3}+0.15 \sigma_{c p}\right] b_{w} d
$$

$k=1+\sqrt{200 / d} \leq 2$ ( $d$ in $\mathrm{mm}$ ) being a suitable coefficient able to take into account the size effect, the geometric ratio of longitudinal reinforcement and the actual compressive stress. Conversely, the share $V_{s w}$ is estimated considering a simple lattice with a concrete upper chord and a lower chord consisting of longitudinal steel rebar connected by means of web diagonal rebars (Figure 21), obtaining $V_{s w}=A_{s w} f_{y w} \sin \alpha$

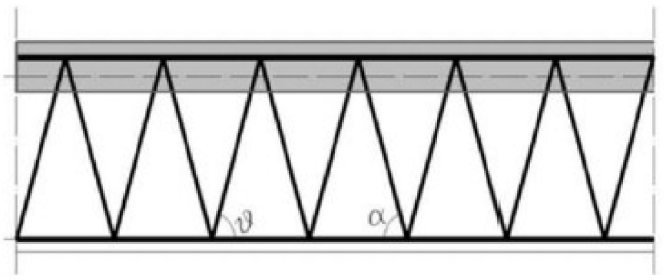

Figure 21. Scheme of the truss system according to Amadio et al. [25].

Finally, the model derived by Chisari and Amadio [16]. was calibrated according to the results of a parametric FE analysis interpreting the results of some of the experimental tests described in the previous section. In the formulation, the shear mechanism is derived on the basis of an analogy 
with the behavior of a concrete panel reinforced through a steel tie, where the panel experiences diagonal compression along the unloaded diagonal direction. In the HSCTB an analogous behavior is recognized for the diagonal web bars that connect the two chords. Thus, once the stress state in the element of the hyperstatic model of the structure is evaluated, suitably exploiting the results of FE analysis for characteristic parameter evaluation, the shear strength of the element can be assessed by summation of the concrete and web steel rebars according to the following expressions:

$$
\begin{gathered}
V_{c}=\frac{f_{c}^{\prime} f_{c t}}{0.66 f_{c}^{\prime}+\gamma f_{c t}} b h \\
V_{s w}=\left(A_{s w} f_{y w}-\frac{V_{c}}{\sin \alpha} \frac{1}{k_{2}\left(\frac{1}{k_{1}}+\frac{a}{E A_{s w} \cos \alpha}\right)}\right) \sin \alpha
\end{gathered}
$$

where $\gamma=1.99$ (when a more detailed evaluation as a function of the ratio $s / h$ according to [16] is not performed), $k_{1}=0.963 G b \sin \alpha, G$ being the shear modulus of the concrete and $h$ the truss height, and

$$
k_{2}=k_{1}\left(1+\left(\frac{s}{h}-0.628\right)^{-2}\right)
$$

To the second class (truss models) there belong the models provided by the current European [39] and Italian [44] codes for conventional reinforced concrete beams, and two composite mechanical models recently proposed on purpose for HSTCBs, namely those of Monti and Petrone [18] and Campione et al. [19].

The truss models with variable strut inclination proposed in the EC2-04 [40] and DM-08 [44] codes estimate the beam shear strength as the minimum of those able to produce collapse of the concrete compressed diagonal strut $V_{R c}$ and of the tensile web reinforcement $V_{R s}$, evaluated as follows

$$
\begin{gathered}
V_{R c}=v \alpha_{c} 0.9 d f_{c}^{\prime} b_{w} \frac{\cot \theta+\cot \alpha}{1+\cot ^{2} \theta} \\
V_{R s}=0.9 d \frac{A_{s w}}{s} f_{y w}(\cot \theta+\cot \alpha) \sin \alpha
\end{gathered}
$$

where the softening coefficient $v$ can be assumed as $v=0.5$ according to DM-08 [44] and equal to $v=0.6\left(1-f_{c}^{\prime} / 250\right)$ according to EC2-04 [40], and $\alpha_{c}=1$ for non-prestressed beams. The concrete strut inclination $\theta$ can be chosen in order to maximize the beam shear strength in the range $1 \leq \cot \theta \leq 2.5$. Since $V_{R}=\operatorname{Min}\left[V_{R s} ; V_{R c}\right]$, the inclination $\theta$ of the concrete strut can be obtained by equating the right-hand sides of Equations (23) and (24), giving:

$$
1 \leq \cot \theta=\sqrt{v \frac{s b_{w} f_{\mathcal{c}}^{\prime}}{A_{s w} f_{y w} \sin \alpha}-1} \leq 2.5
$$

Monti and Petrone [18] suggested a complex model for evaluating the shear strength of HSTCBs based on extensive finite element analysis. The authors identified a crisis mechanism characterized by yielding of $n$ pairs of diagonal bars, which is activated before crushing of the concrete. In order to speed up the shear strength evaluation procedure, they formulated a simplified method in which the concrete is assumed to be able to carry the increment of load caused by premature yielding of a pair of web reinforcements.

Recently, Campione, et al. [19] proposed a hybrid model based on the additive approach, where the contribution of the reinforced concrete is evaluated by taking into account both the arch effect and the beam effect. The latter is governed by the discontinuity in the bottom chord forces induced by the concentrate action exerted by the diagonal web bars, and the residual bond stress in the adjunctive rebar that integrates the reinforcement of the bottom steel plate. 
Lastly, it has to be stressed that, among the models derived for conventional reinforced concrete beams, those derived for beams reinforced by means of stirrups with two different inclinations [46], recently improved for beams strengthened by external reinforcement [47], have also been successfully applied for prediction of the shear strength of HSTCBs [17].

Again, it has to be stressed that most of the experimental investigations and the derived analytical models concern HSTCBs with bottom chord made up of steel plate, whereas there is a lack of knowledge on the shear behavior of beams with precast prestressed concrete bottom chord.

\section{Conclusions}

Although Hybrid Steel Trussed Concrete Beams (HSTCB)s have been utilized since the 1970s in many countries in Europe, Asia, and Central and South America, for almost forty years' design of this typology has been conducted using models and design methods formulated for conventional steel and concrete composite beams, or for reinforced concrete beams. Recently, against the background of research and regulatory innovative formulations of models and calculation methods for evaluation of shear strength of concrete and composite elements, a new impulse to research performed on purpose for HSTCBs has been generated. Thus, researchers have performed experimental tests and formulated calculation models for assessment of HSTCB capacity. Many of them are devoted to investigating two topics, namely the stress transfer mechanism between the steel lattice and the concrete core, and the shear strength of HSTCBs.

The test results and the models recently proposed in the literature are reviewed here, stressing when they are derived by extension of models formulated for different element typologies, or derived on purpose for HSTCBS.

It is emphasized that regarding the first topic, many experimental push-out tests were performed, using the procedures codified in the codes for conventional steel concrete composite beam. The results show that proper sizing of the welding and of the web reinforcement make it possible to avoid brittle failure of the connection, ensuring development of a ductile collapse mechanism, characterized by the collapse of the concrete subsequent to yielding of the web reinforcement. The models derived on purpose are able to assess both the stiffness [7] and the strength [11] of the connection.

Regarding the shear strength of the beam, the collapse mechanism is strongly influenced by the relative strength between the web steel reinforcement and the concrete, and by the bond between reinforcing bars and concrete, i.e., by the type and surface finishing of the steel bars. Evaluation of shear resistance in design-oriented model is mainly performed by extending and suitably adapting design models for conventional reinforced beams to the case of HSTCBs. More complex models derived on purpose for this typology $[18,19]$ are more efficient, but are more suitable for analysis of previously designed structures (analysis-oriented models).

However, it has to be highlighted that, often in the construction practice, rebars are added and welded to the bottom chord steel plate, in order to increase both the capacity of the connection, and increase the shear strength. None of experiments and models in the literature analyzed the effect of this technical solution on the steel truss to concrete connection capacity. Moreover, several tests proved the large effect that this technical solution has on the shear strength of the beam, but the available models do not adequately reproduce it because they do not consider the collaboration of the added rebars and steel plate ensured by the welds.

Finally, it has to be emphasized that there is a lack of knowledge on the connection capacity and shear behavior of beams with precast prestressed concrete bottom chord.

Author Contributions: Piero Colajanni, Lidia La Mendola and Alessia Monaco had equal contribution to all the actions necessary for the realization of the paper.

Conflicts of Interest: The authors declare no conflict of interest. 


\section{References}

1. Vv.Aa. Guida Tecnico Operativa per il Professionista. Progettare con le Travi Prefabbricate Reticolari Miste PREM (Technical Guide for designer. Design with Hybrid Steel Trussed-Concrete Beams HSTCBs); Tecniche Nuove eds.: Milan, Italy, 2011; ISBN 978-88-481-2636-6. (In Italian)

2. Colajanni, P.; La Mendola, L.; Recupero, A. Experimental test results vs. analytical prediction of welded joint strength in Hybrid Steel Trussed Concrete Beams (HSTCBs). EJECE 2013, 17, 742-759. [CrossRef]

3. Vincenzi, L.; Savoia, M. Stabilita' di tralicci PREM in prima fase (Stability of PREM-beams in the first phase). In Proceedings of the 18th C.T.E. Congress, Brescia, Italy, 11-13 November 2010; pp. 849-858. (In Italian)

4. Puhali, R.; Smotlack, I. Relazione sulle prove di push-out atte a determinare le leggi di carico-scorrimento delle travi in sistema composto tipo"REP" (Report on the Push-Out Tests Fit for the Determination of Load-Slip Laws of REP Composite Truss Beams); Science of Constructions Institute Acts, University of Trieste: Triest, Italy, 1980.

5. Aiello, M.A. Analisi sperimentale della connessione acciaio-calcestruzzo nelle travi reticolari miste (Experimental Analysis of Steel-Concrete Connection in Hybrid Truss Beams). In Proceedings of the 7th Italian Workshop on Composite Structures, Benevento, Italy, 23-24 October 2008; pp. 33-42.

6. Cancelliere, N.; Colajanni, P.; La Mendola, L. On bottom steel plate to concrete anchorage in hybrid steel trussed concrete beams. In Proceedings of the STESSA 2012-Behaviour of Steel Structures in Seismic Areas, Santiago, Chile, 9-11 January 2012; CRC Press/Balkema Publishers-Taylor \& Francis Group: London, UK, 2011; pp. 243-248, ISBN 9780415621052.

7. Tullini, N.; Minghini, F. Nonlinear analysis of composite beams with concrete-encased steel truss. J. Constr. Steel Res. 2013, 91, 1-13. [CrossRef]

8. Colajanni, P.; La Mendola, L.; Monaco, A. Stress transfer mechanisms investigation in hybrid steel trussed-concrete beams by push-out tests. J. Constr. Steel Res. 2014, 95, 56-70. [CrossRef]

9. Monaco, A. Experimental Analysis, Numerical and Analytical Modeling of Shear Strength Mechanisms in Hybrid Steel Trussed Concrete Beams. Ph.D. Thesis, Department of Civil, Environmental, Aerospatial and Material Engineering, University of Palermo, Palermo, Italy, 2014.

10. Colajanni, P.; La Mendola, L.; Latour, M.; Monaco, A.; Rizzano, G. FEM analysis of push-out test response of Hybrid Steel Trussed Concrete Beams (HSTCBs). J. Constr. Steel Res. 2015, 111, 88-102. [CrossRef]

11. Colajanni, P.; La Mendola, L.; Latour, M.; Monaco, A.; Rizzano, G. Analytical prediction of the shear connection capacity in precast steel-concrete trussed beams. Mater. Struct. 2017, 50. [CrossRef]

12. Colajanni, P.; La Mendola, L.; Monaco, A. Stress transfer and failure mechanisms in steel-concrete trussed beams: Experimental investigation on slab-thick and full-thick beams. Constr. Build. Mater. 2018, 161, 267-281. [CrossRef]

13. Badalamenti, V. Analisi teorico-sperimentale del comportamento ciclico delle connessioni tra travi prefabbricate reticolari miste e pilastri in cemento armato. (Theoretical and Experimental Analysis of the Cyclic Behavior of Hybrid Steel Trussed Concrete Beam-to-Column Connections). Ph.D. Thesis, Università degli Studi di Palermo-Dipartimento di Ingegneria Strutturale, Aerospaziale e Geotecnica, Palermo, Italy, 2010.

14. Badalamenti, V.; La Mendola, L.; Colajanni, P. Seismic behavior of hybrid steel trussed concrete beams. In Proceedings of the 14th European Conference Earthquake Engineering, Ohrid, Republic of Macedonia, 30 August-3 September 2010; pp. 1-8.

15. Tesser, L.; Scotta, S. Flexural and shear capacity of composite steel truss and concrete beams with inferior precast concrete base. Eng. Struct. 2013, 49, 135-145. [CrossRef]

16. Chisari, C.; Amadio, C. An experimental, numerical and analytical study of hybrid RC-encased steel joint beams subjected to shear. Eng. Struct. 2014, 61, 84-98. [CrossRef]

17. Colajanni, P.; La Mendola, L.; Monaco, A. Validation of a shear model for RC and hybrid beams with two different inclinations of transversal reinforcement. In Proceedings of the 2nd International Symposium on Advances in Civil and Infrastructure Engineering (ACE), Vietri, Italy, 12-13 June 2015.

18. Monti, G.; Petrone, F. Shear resisting mechanisms and capacity equations for composite truss beams. J. Struct. Eng. 2015, 141. [CrossRef]

19. Campione, G.; Colajanni, P.; Monaco, A. Analytical Evaluation of Steel-Concrete Composite Trussed Beam Shear Capacity. Mater. Struct. 2016, 49, 3159-3176. [CrossRef] 
20. Colajanni, P.; La Mendola, L.; Monaco, A. Experimental Investigation on the Shear Response of Precast Steel-Concrete Trussed Beams. ASCE J. Struct. Eng. 2017, 143, 04016156. [CrossRef]

21. Calvi, G.M.; Magenes, G.; Pampanin, S. Relevance of beam-column joints damage and collapse in rc frame assessment. J. Earthq. Eng. 2002, 6, 75-100. [CrossRef]

22. Russo, G.; Somma, G. Shear strength of R/C beam-Column joints without shear reinforcement under severe seismic loading. Stud. Res. 2002, 23, 135-165.

23. Ju, Y.K.; Kim, J.Y.; Kim, S.D. Experimental evaluation of new concrete encased steel composite beam to steel column joint. ASCE J. Struct. Eng. 2007, 133, 519-29. [CrossRef]

24. Amadio, C.; Macorini, L.; Suraci, G. Structural performance of a new hybrid RC-encased steel joint system. In Advances in Reinforced Concrete and Precast Constructions; Di Prisco, M., Ed.; Strarrylink: Milan, Italy, 2008; pp. 19-29.

25. Amadio, C.; Macorini, L.; Sorgon, S.; Suraci, S. A novel hybrid system with RC-encased steel joists. EJECE 2011, 15, 1433-1463. [CrossRef]

26. Hsu, H.L.; Hsieh, J.C.; Juang, J.L. Seismic performance of steel-encased composite members with strengthening cross-inclined bars. J. Constuct. Steel Res. 2004, 60, 1663-1679. [CrossRef]

27. Kuramoto, H.; Nishiyama, I. Seismic performance and stress transferring mechanism of throughcolumn-type joints for composite reinforced concrete and steel frames. ASCE J. Struct. Eng. 2004, 130, 352-360. [CrossRef]

28. Sassone, M.; Chiorino, M.A. Design Aids for the Evaluation of Creep Induced Structural Effects; Shrinkage and Creep of Concrete; Gardner \& Weiss: New York, NY, USA, 2005; pp. 239-259.

29. European Committee for Standardization (CEN). EN1994-1: Eurocode 4: Design of Composite Steel and Concrete Structures. Part 1-1: General Rules and Rules for Buildings; CEN: Brussels, Belgium, 2004.

30. Newmark, N.M.; Siess, C.P.; Viest, I.M. Tests and analysis of composite beams with incomplete interaction. Proc. Soc. Exp. Stress Anal. 1951, 9, 75-92.

31. Amadio, C.; Fragiacomo, M. A Finite element model for the study of creep and shrinkage effects in composite beams with deformable shear connections. Costruzioni Metalliche 1993, 4, 213-228.

32. Broms, B.B. Lateral Resistance of piles in cohesive soils. J. Soil Mech. Found. Div. 1964, 90, $27-63$.

33. Vintzeleou, E.N.; Tassios, T.P. Mathematical Models for Dowel Action under Monotonic and Cyclic Conditions. Mag. Concr. Res. 1986, 38, 12-22. [CrossRef]

34. Vintzeleou, E.N.; Tassios, T.P. Behavior of dowels under cyclic deformation. ACI Struct. J. 1987, 84, 18-30.

35. Vintzeleou, E.N.; Tassios, T.P. Eccentric Dowels Loaded against core of Concrete Sections. J. Struct. Eng. 1990, 116, 10. [CrossRef]

36. Millard, S.G.; Johnson, R.P. Shear transfer across cracks in reinforced concrete due to aggregate interlock and to dowel action. Mag. Concr. Res. 1984, 36, 126. [CrossRef]

37. European Committee for Standardization (CEN). EN1993-1-1: Eurocode 3: Design of Steel Structures. Part 1-1: General Rules and Rules for Buildings; CEN: Brussels, Belgium, 2005.

38. Izzo, L.; Minelli, F.; Plizzari, G. Le travi reticolari miste nel cammino verso la normativa. (The hybrid trussed beams on the path toward the code). In Proceedings of the 16th C.T.E. Congress, Parma, Italy, 9-11 November 2006. (In Italian)

39. European Committee for Standardization (CEN). EN 1992-1-1:1992 Design of Concrete Structures-Part 1-1: General Rules and Rules for Buildings; Eurocode 2; CEN: Brussels, Belgium, 1992.

40. European Committee for Standardization (CEN). EN 1992-1-1:1:2004 Design of Concrete Structures-Part 1-1: General Rules and Rules for Buildings; Eurocode 2; CEN: Brussels, Belgium, 2004.

41. American Concrete Institute (ACI). Bulding Code Requirements for Structural Concrete and Commentary; ACI 318M-08; ACI: Farmington Hills, MI, USA, 2008.

42. Canadian Standards Association (CSA). Design of Concrete Structures; CAN CSA A23.3-04; CSA: Rexdale, ON, Canada, 2004.

43. Ministry of Public Works Decree (D.M.LL.PP.). Norme Tecniche per le Costruzioni (Construction Technical Codes); Gazzetta Ufficiale Repubblica Italiana: Rome, Italy, 1996. (In Italian)

44. Ministry of Public Works Decree (D.M.LL.PP.). Norme Tecniche per le Costruzioni (Construction Technical Codes); Gazzetta Ufficiale Repubblica Italiana: Rome, Italy, 2008. (In Italian) 
45. Bentz, E.C.; Collins, M.P. Simplified form of the modified compression field theory for the analysis of beams. In Proceedings of the 2nd International Conference Fib, Fédération internationale du béton/International Federation for Structural Concrete (fib), Naples, Italy, 5-8 June 2006; pp. 3-56.

46. Colajanni, P.; La Mendola, L.; Mancini, G.; Recupero, A.; Spinella, N. Shear Capacity in Concrete Beams Reinforced by Stirrups with Two Different Inclinations. Eng. Struct. 2014, 81, 444-453. [CrossRef]

47. Colajanni, P.; La Mendola Recupero, A.; Spinella, N. Stress field model for strengthening of shear-flexure critical RC beams. ASCE J. Comp. Constr. 2017, 21, 04017039. [CrossRef] 